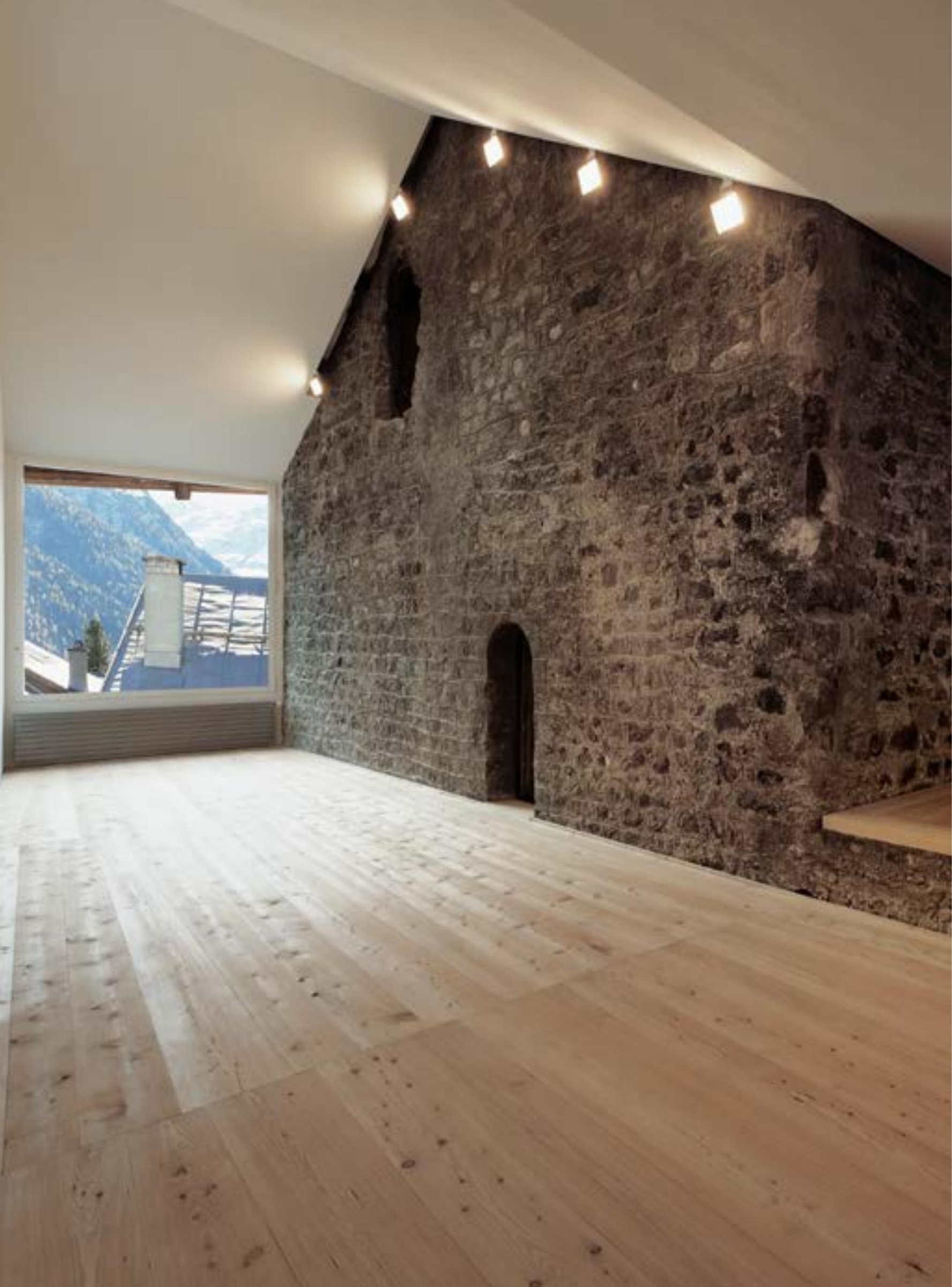




\title{
Die Zeitgenossenschaft des Alten im Engadin
}

\author{
The contemporaneity of the ancient in the Engadine
}

\author{
Architecture: Hans-Jörg Ruch \\ Photography: Filippo Simonetti
}

\begin{abstract}
The Engadinerhaus is a typical historic Engadine collective building that combines all the functions of a farm and a residence into a single housing system. It is characterized by a distribution and structural scheme organized according to certain principles that give the artifacts an imposing and severe external appearance. These are very old buildings whose matrix can be placed between the fourteenth and seventeenth centuries and which have undergone numerous transformations over time in order to adapt them to the changing needs of the agricultural world. The historical and documentary value of these important testimonies is already recognized at the beginning of the twentieth century and in 1905 the "Bündner Heimatschutz" is already promoting their protection in order to preserve their architectural and building features.

The architect Hans-Jörg Ruch has recently worked on some projects for the re-functioning and restoration of these extraordinary buildings, which in some cases have kept their residential use, while in other cases they have been converted into exhibition spaces and art galleries.

The buildings presented in this essay - such as the Chesa Andrea in Madulain, the Chesa Büsin in Silvaplana, the Chesa Madalena in Zuoz, the Chesa Merleda in La Punt, the Chesa Not in Tschlin and the Chesa Perini in S-Chanf - are just one selection of the works realized in Engadine by Ruch. New interior volumes, such as a "house in the house", or even veils and walls with shapes and materials that strongly reveal their contemporaneity, are inserted in the original spaces of the old building left unaltered. These interventions show an unprecedented and original dialectic between the preservation of the materic character of the historical artifact and the unveiling of new meanings and spatiality, through architectural, constructive and material solutions affected by contemporary artistic procedure.
\end{abstract}

The texts are taken from the book «Close-up - Ruch \& Partner Architects 1994-2018» edited by Scheidegger \& Spiess, 2018.

\section{Hans-Jörg Ruch}

Born in 1946 in Bellach, Switzerland, he graduated in architecture at the ETH in Zurich in 1971 and in 1973 he obtained a Master Degree in Architecture at the Rensselaer Polytechnic Institute in Troy, New York, USA where he has become a visiting professor since 1990.

From 1974 to 1977 he worked in Switzerland with the Obrist and Partners studio. He has collaborated with the architect Urs Hüsler since 1977. In 1989 he established his own studio in St. Moritz, which became Ruch \& Partners Architects Ltd. in 2010.

\section{Filippo Simonetti}

Born in Ascoli Piceno in 1944. After completing a degree in literature and philosophy at the University of Urbino, he made his passion for architecture and photography into his profession. His works have been shown at a great many exhibitions, including the VI. and the XV. Architecture Biennale in Venice in 1996 and 2016. He lives in Brunate.

\section{Keyword}

Engadine, heritage, contemporary architecture, arts. 


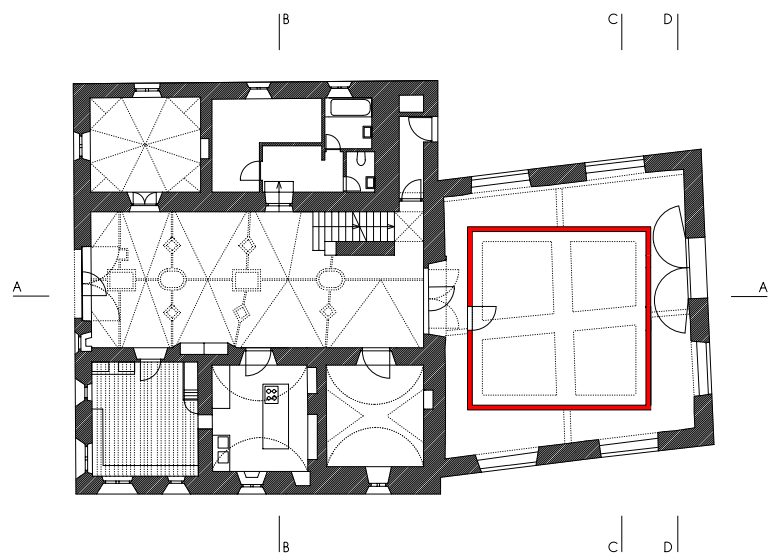

\section{Chesa Perini, S-chanf}

Erbaut um 1600 unter Verwendung eines mittelalterlichen Vorgängerbaus, erweitert um 1676, restauriert 1987/1988, Kunstgalerie eingebaut 2006.

Die Chesa Perini ist Teil einer Gruppe aristokratischer Wohnsitze unmittelbar westlich der Kirche von S-chanf, die in ihrer herrschaftlichen Ausformung alle auf das Geschlecht der Perini zurückgehen. Die Perini waren im 17. und 18. Jahrhundert unangefochten die «erste» Familie im Ort. Der Bau zeigt exemplarisch jene etappenweise Entstehung auf, wie sie, in jeweils spezifischer Form, die Mehrzahl der historischen Häuser im Engadin auszeichnet. Aus einem turmartigen Steinhaus wohl spätmittelalterlichen Ursprungs entsteht um 1600 ein stattliches Bauernhaus nach dem Schema des Engadinerhauses mit einem mächtigen Sulèr, einer längsseitig daran angegliederten dreiräumigen Wohnzeile und einem rückwärtig angebauten, intern erschlossenen Ökonomieteil. Das bemerkenswerte Gewölbe im Sulèr deutet auf den bereits in dieser Bauphase sehr gehobenen Standard des Hauses hin. Um 1676 wird das Gebäude erhöht, nach Norden erweitert und edel ausgestattet. Der Sulèr, dessen Funktion als Durchfahrt zur Scheune gewahrt bleibt, wird durch diese Erweiterung zum Mittelkorridor. So nähert sich die Chesa Perini vom Grundriss her dem Typus des italienischen Palazzo an, dem damals bevorzugten Baumodell der aristokratischen Führungsschicht Graubündens. Wie die Chesa Merleda in La Punt ist die Chesa Perini ein besonders eindrückliches Beispiel für eine Verbindung des Bürgerhauses herrschaftlichen Anspruchs mit dem bäuerlichen Betrieb. Die Entwicklung vom Bauern- zum prächtigen Herrschaftshaus konnten wir anhand der Pläne erahnen. Sie bestätigte sich, als wir 1988 fast den ganzen morschen Verputz von den Bruchsteinmauern ablösen mussten. Die Fugen zwischen den einzelnen Etappen waren ersichtlich. Wir entfernten störende Anbauten, fügten die nötigen Sanitäranlagen sowie eine zentrale kombi-

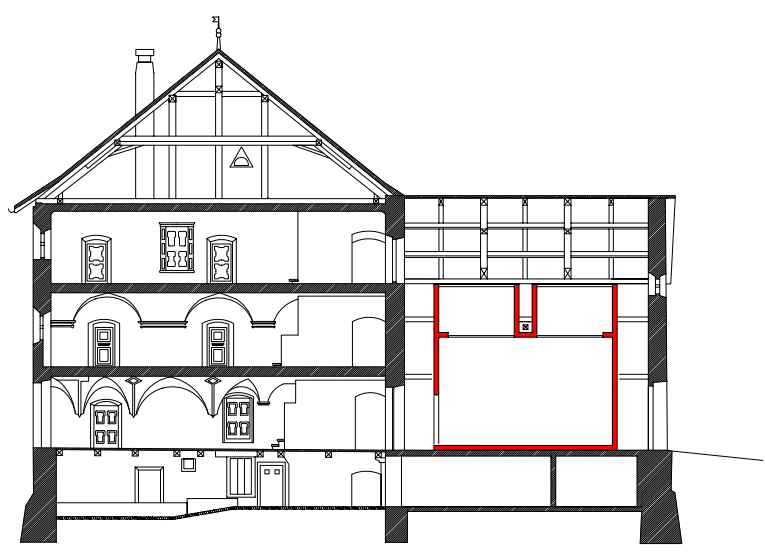

nierte Öl-Holz-Heizung in bestehende Räume ein. Die historische Raumstruktur blieb integral erhalten. Wir konnten den riesigen Heustall als grossen Kaltraum belassen, er diente in der Folge als Abstellraum und Holzlager. Fast zwanzig Jahre später erwies sich die leere Halle als Glück für die neuen Besitzer: Sie wollten im Haus eine Kunstgalerie einrichten, und der Heustall bot dafür den idealen Ort. Wir bauten einen unabhängigen und selbsttragenden, thermisch isolierten Kubus mit 7 Meter Kantenlänge ein, der mit Bitumen bestrichen wurde. Alt und Neu durchdringen und berühren sich nirgends; man kann den Block umrunden, wobei man zwischen dessen exakten und den unregelmässigen Aussenwänden des Heustalls durch spannende Zwischenräume schreitet. Der Kunstraum behauptet sich als eigenständiges, stimmungsvolles Element, ohne die Integrität der alten Konstruktion anzutasten. Steht das Tor zwischen Heustall und Sulèr offen, ist dieser schwarze Block zu sehen. Der oberste Teil des Kunstblocks dient als Lichtgaden: Etwas Tageslicht tritt von oben ein und wird flächig nach unten gestreut. Das Kunstlicht, das ebenfalls in diesen Gaden integriert ist, beleuchtet den Innenraum des Kubus und erhellt zugleich den Dachraum des Heustalls. Dieser obere Teil ist eingepasst in die kreuzförmige, aussteifende Holzkonstruktion des Heustalls. Die sich kreuzenden Balken teilen die Oblichtsektoren des Kunstraums ein und bestimmen deren Lage. So spürt man im Galerieraum stets auch den alten Stall dahinter. Wenn man als Besucher durch das äussere Tor in den Heustall tritt, steht man direkt vor dem schwarzen Block, findet jedoch keinen Eingang. Erst nach einigen Schritten kommt die Ahnung auf, dass der $\mathrm{Zu}$ gang zum Kunstraum wohl auf der anderen Seite liegen muss, gegenüber dem Tor zum Sulèr. Nur eine schlichte Türfalle deutet den Eingang an. Zwischen dem dunklen Zwischenraum und dem inneren «white cube» liegt nur ein kleiner Schritt, doch die Stimmung ändert markant. 

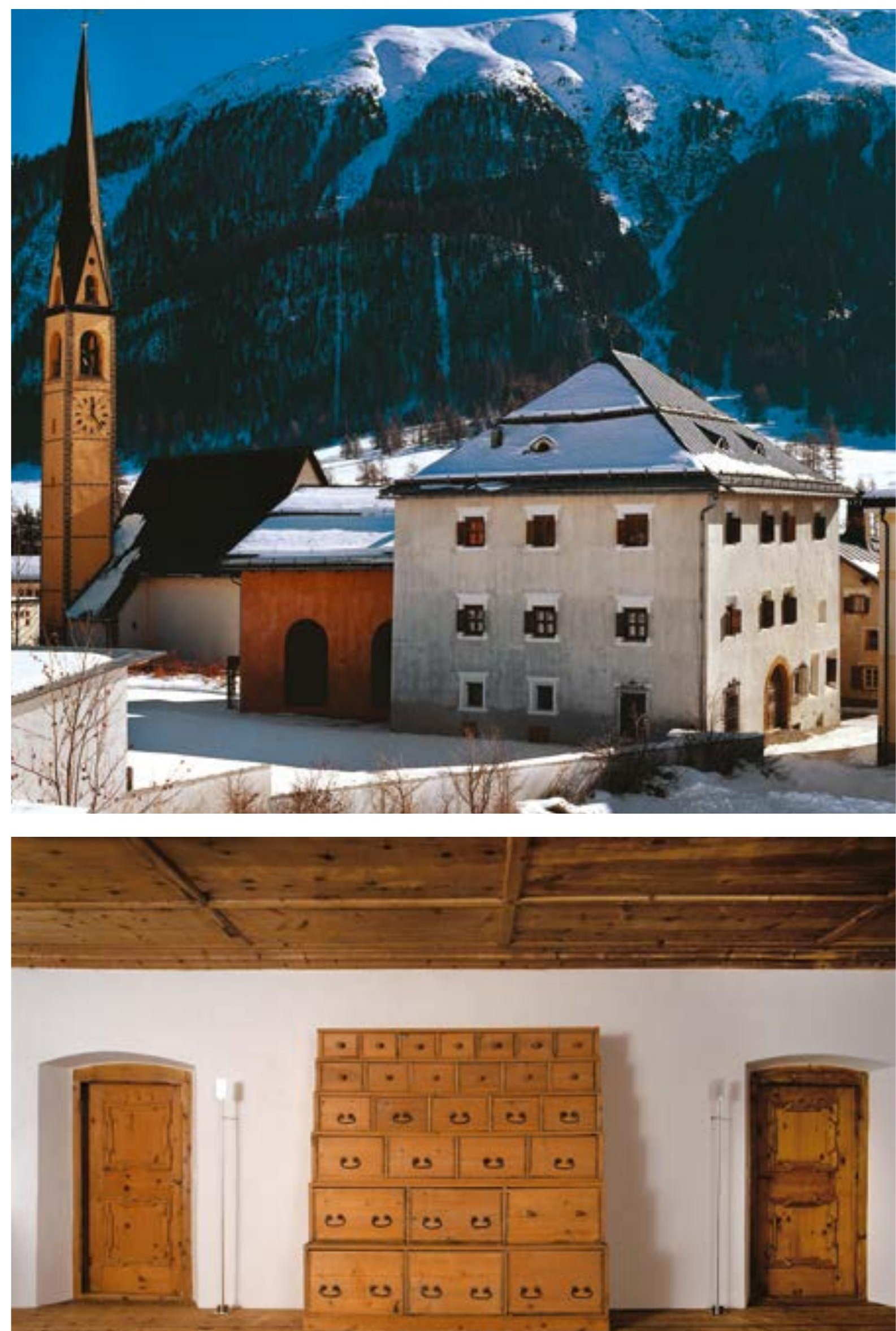

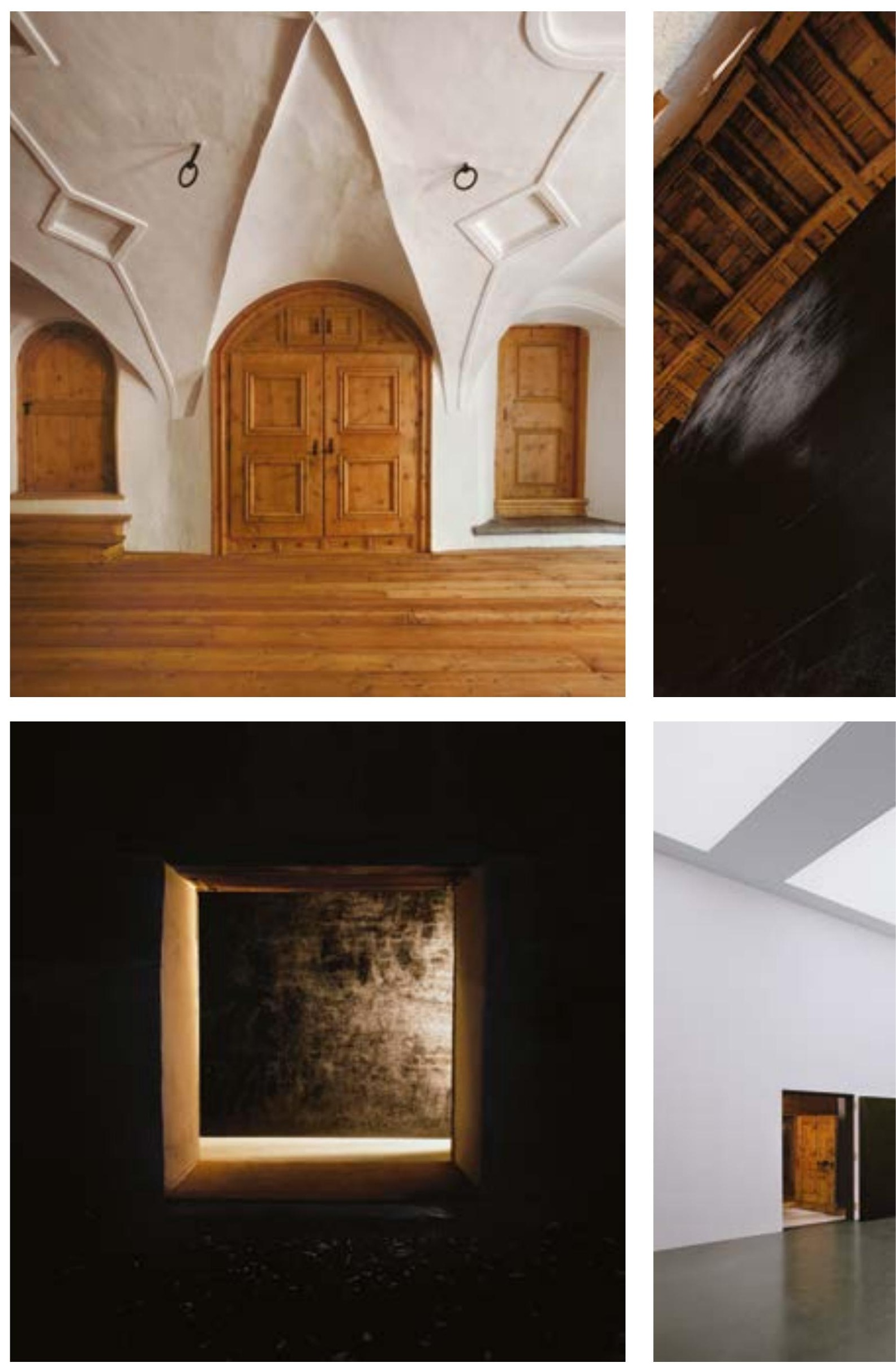

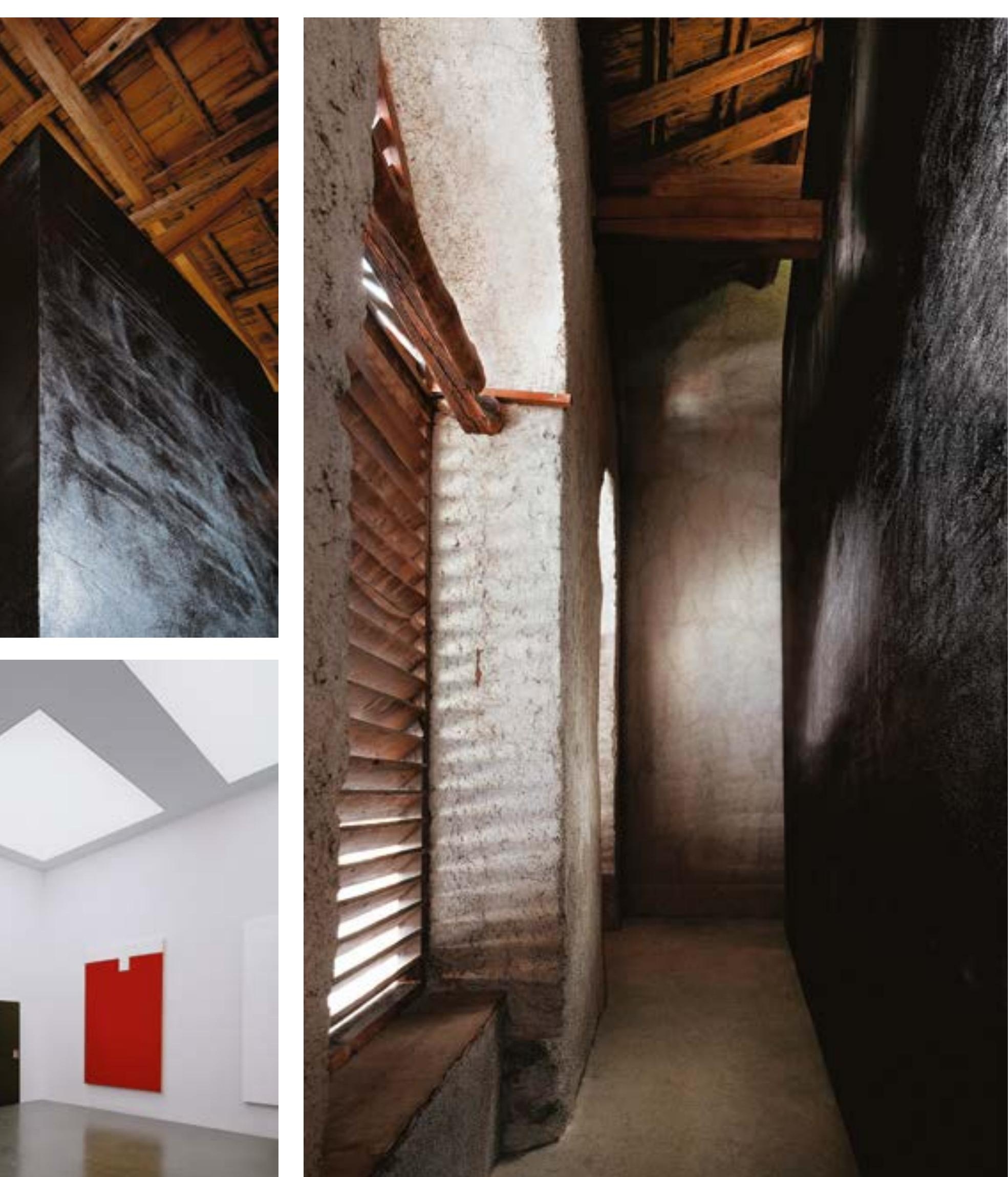


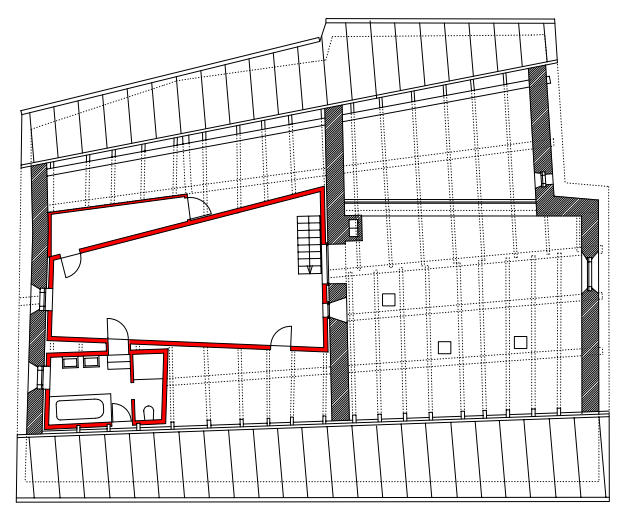

\section{Chesa Andrea, Madulain}

Erbaut zwischen 1510 und 1520 unter Verwendung eines mittelalterlichen Vorgängerbaus, erweitert in der zweiten Hälfte des 16. Jahrhunderts, umgebaut 1640, restauriert und umgebaut 1997/1998.

Die Chesa Andrea in Madulain ist in baugeschichtlicher Hinsicht besonders interessant, handelt es sich doch um eines der ältesten Gebäude, in dem sich der Typus Engadinerhaus in seiner Grundform bauarchäologisch fassen lässt. Das Haus integriert zwei ungleich alte mittelalterliche Gebäude unterschiedlicher Funktion: einen steinernen, nur noch im Unterbau erhaltenen Wohnturm wohl des 13./14. Jahrhunderts, der sich über einem quadratischen Grundriss von 5,5 × 5,5 Metern erhebt, sowie die Grundmauern einer jüngeren, vermutlich im 15. Jahrhundert entstandenen Stallscheune. Die beiden Bauten standen ursprünglich frei, in einem Abstand von rund 5 Meter zueinander. Zwischen 1510 und 1518 (Dendrodaten) wurden die wahrscheinlich im Schwabenkrieg von 1499 beschädigten Gebäude wiederaufgebaut und zusammengefasst, Wohn- und Ökonomietrakt also in einem Haus vereint. Im Unter- und Erdgeschoss entstanden dabei jene internen Durchfahrten, wie sie für das Engadinerhaus charakteristisch sind. Seine gültige Form erhielt das Haus 1640 (Jahreszahl an der Einfahrt zum heutigen Sulèr); damals dürfte auch die gegen Süden auf Konsolen aufgelegte Vormauerung des Strickteils entstanden sein. In der zweiten Hälfte des 16. Jahrhunderts folgte der Anbau zweier übereinanderliegender gewölbter Vorratskammern. Seine sukzessive Entstehung ist besonders für jene neuzeitlichen Bauernhäuser im Engadin typisch, die sich innerhalb des historischen Kerns eines Dorfes befinden. Die Gemeinde erlaubte uns, störende sekundäre Einbauten des 20. Jahrhunderts zu entfernen, bevor wir definitive Pläne für den Umbau einreichen

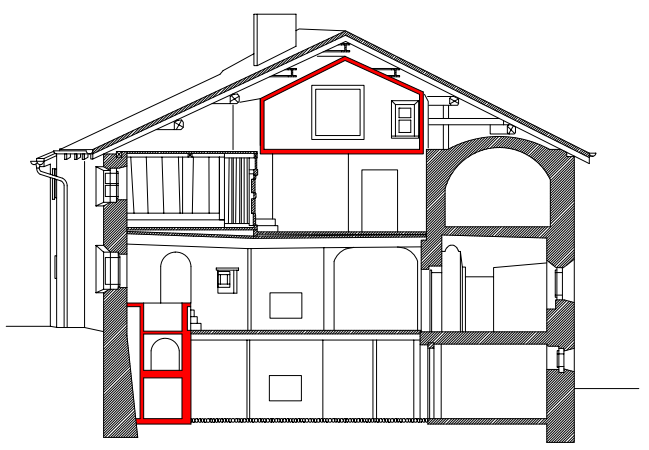

mussten. Das ist nicht selbstverständlich. So blieb Zeit, das Haus eingehend zu erforschen. Als wir wussten, was wir vor uns hatten, konnten wir den Umbau schlüssiger entwerfen. Es gelang uns, die Bauherrschaft zu überzeugen, den riesigen Heustall nicht auszubauen, sondern als Grossraum zu erhalten. Denn das Zusammenspiel des voluminösen Stalls und der übrigen Kleinräume ist ein Wesensmerkmal alter Engadiner Bauernhäuser. Heute ist der Heustall vergleichbar mit einer Piazza in einer italienischen Stadt: ein freier, zugänglicher Raum, der als Lunge wirkt für das introvertierte Haus darum herum. Die meisten Arbeiten an der Chesa Andrea waren restaurativer Art: Wir reinigten alte Partien, richteten und flickten sie und ergänzten Teilstücke, wo es nötig war. Für neue Bereiche wie Küche und Bäder wählten wir eine einfache, zeitgenössische Formensprache und Materialien, die zum Bestand passten, zum Beispiel massives Lärchenholz. Die Küche, wo eine alte offene Feuerstelle entdeckt wurde, blieb am selben Ort, in einem Gewölberaum neben der Stube. Im Raum über der Küche, ebenfalls überwölbt, bauten wir die Bäder ein. Dabei mussten wir zwei Türöffnungen herausbrechen. Sie sind als neue Öffnungen erkennbar, weil sich ihre Proportionen von den alten unterscheiden. Im Sinne des Weiterbauens, wie es seit Jahrhunderten geschah, fügten wir eine grosse Schlafkammer hinzu, ganz in Lärchenholz. Ein gezielter, konzentrierter Eingriff, denn die Kammer ist selbsttragend, sie berührt die historische Dachkonstruktion nirgends. Das erkennbar Neue verankert den Bau in der heutigen Zeit. Am meisten Arbeit steckt in der nach Westen gerichteten Hauptfassade. Wir entfernten den Balkon - kein typisches Element an einem Engadiner Haus - und eine bis zu 3 Zentimeter dicke Verputzschicht. Die Überraschung war gross, als darunter zwei historische, mit farbigem Stempelsgrafitto verzierte Fenster zum Vorschein kamen. 

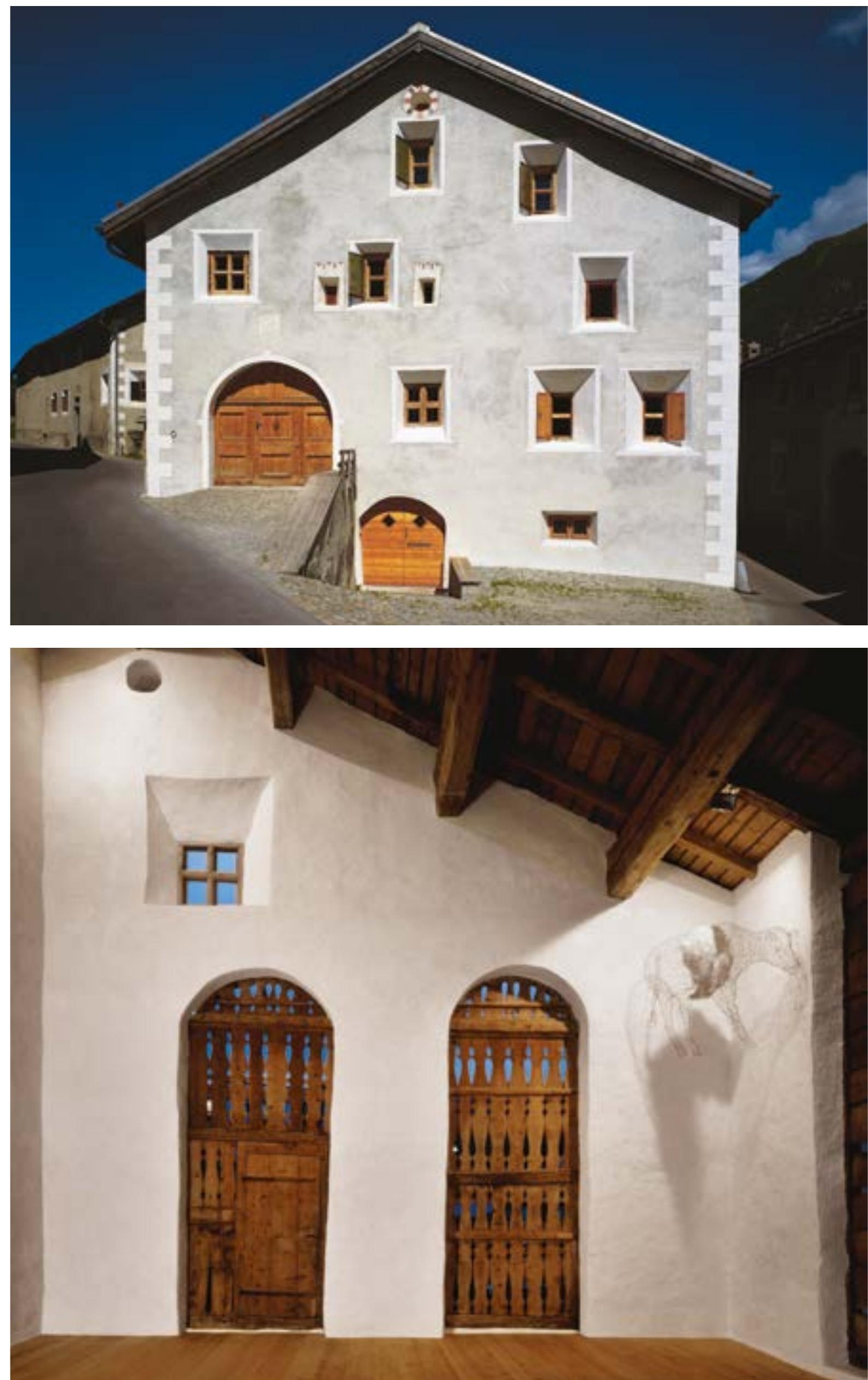

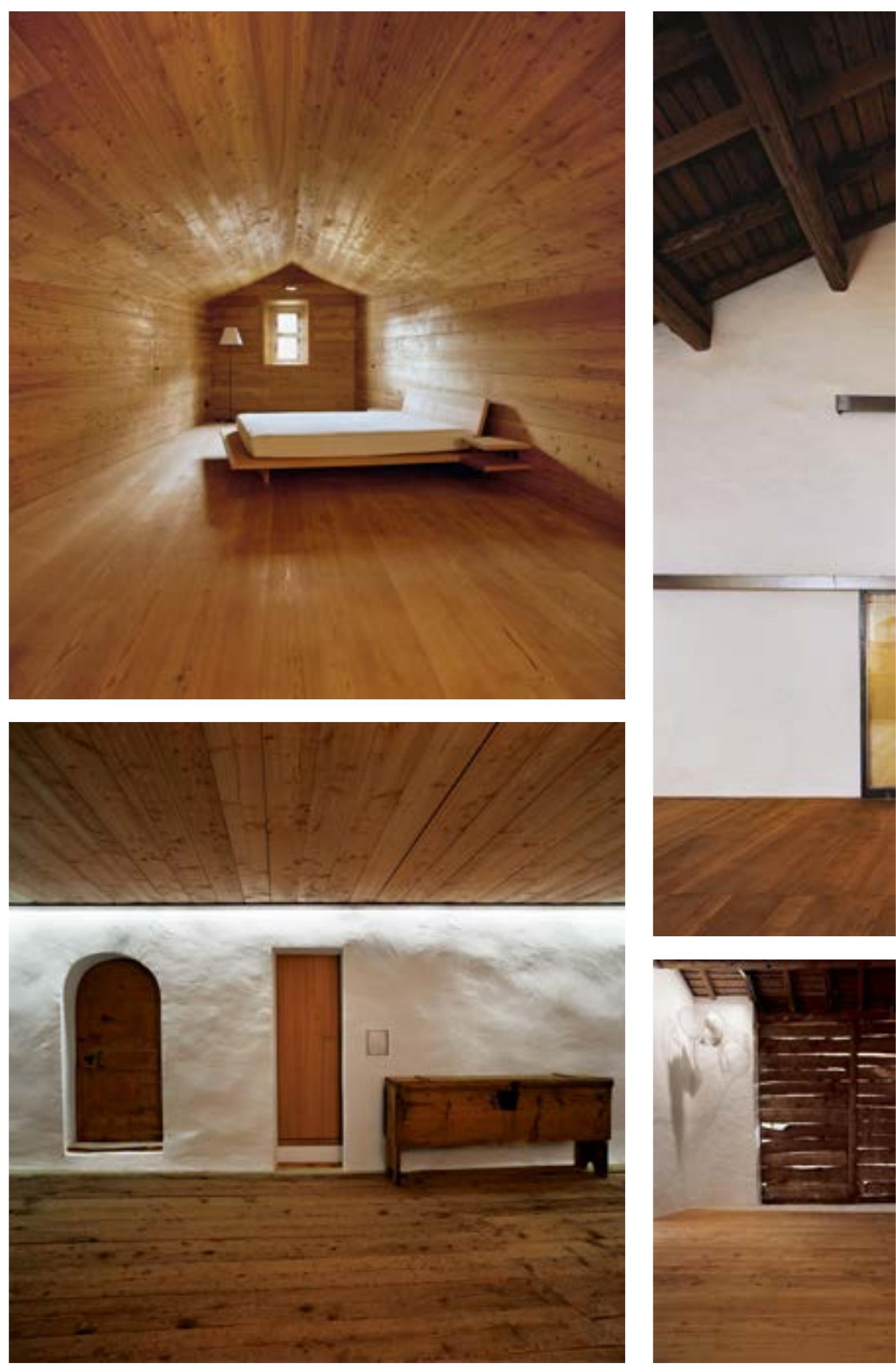

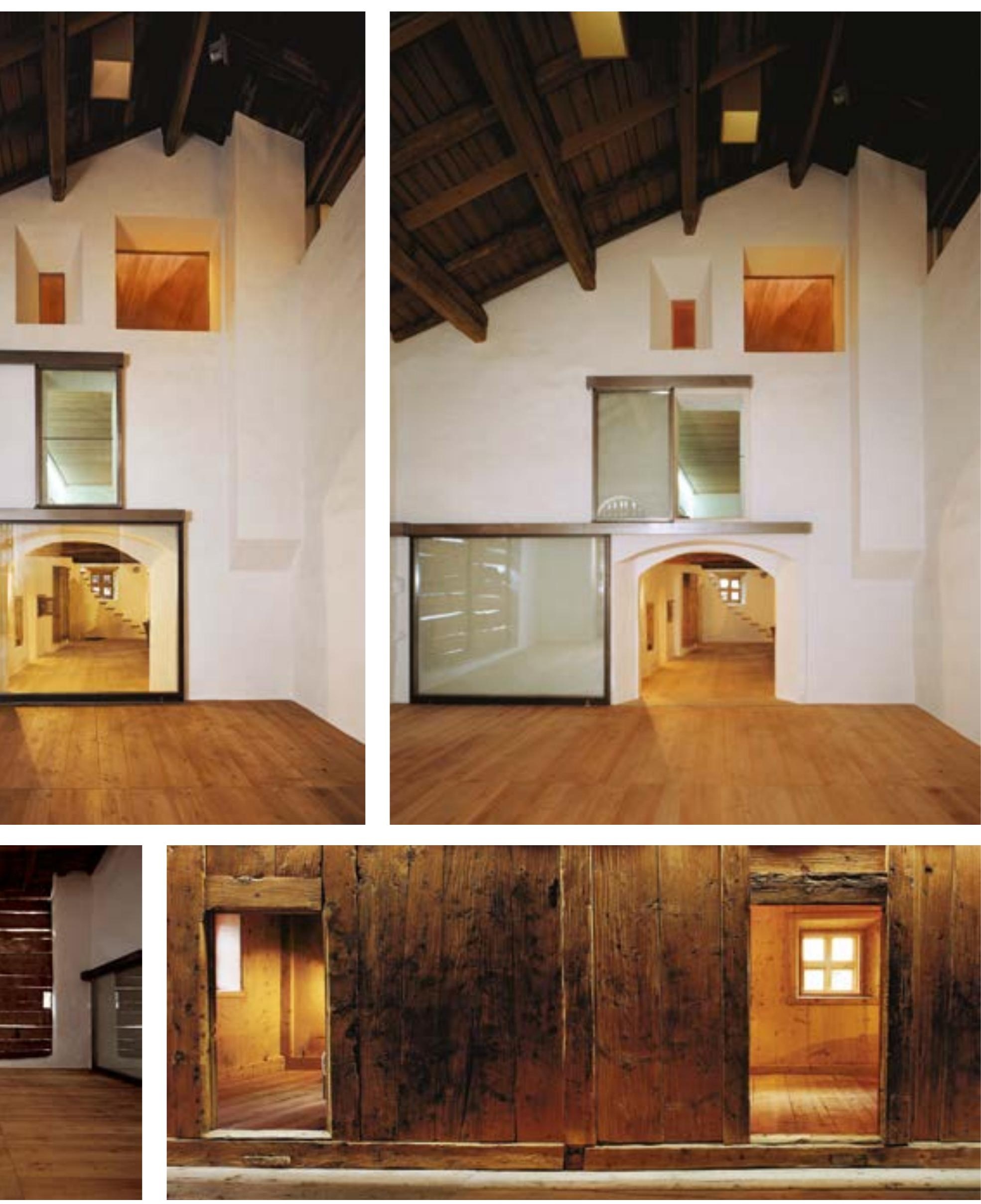

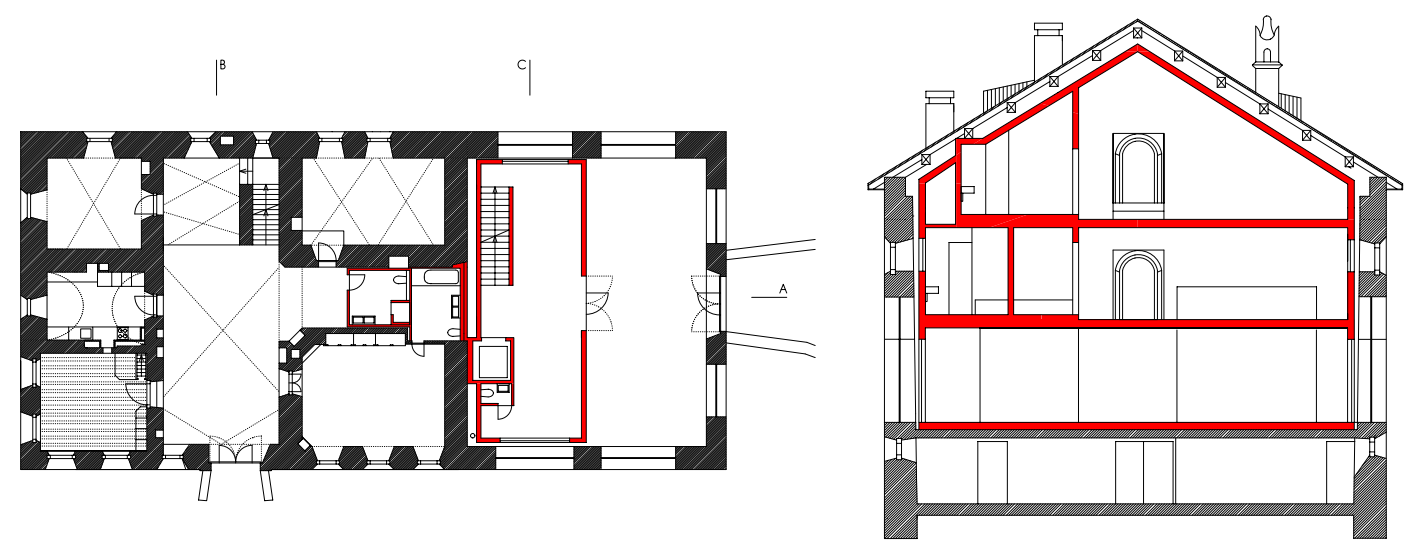

\section{Chesa Merleda, La Punt}

Erbaut 1642-1649; renoviert um 1800, restauriert und umgebaut 1999.

Die Familie Albertini hatte im 17. und 18. Jahrhundert eine dominante Stellung in La Punt inne, ähnlich jener der Perini in S-chanf; sie liess sich in La Punt mehrere Wohnhäuser bauen. Die für Hauptmann Ulrich Albertini auf freier Flur errichtete Chesa Merleda gehört dabei zu den prominentesten «Bürgerhäusern» Graubündens. Der Bau ist allein durch seine Grösse, die einheitliche Gestaltung und die etwas isolierte Stellung imposant. Die Stallfront mit Rundbogenarkaden und der mit Zinnen geschmückte Giebel wirken mindestens so repräsentativ wie der Wohnteil, der auf die zentrale Wegkreuzung im Dorf ausgerichtet ist. Im Innern gehen bäuerliche und herrschaftliche Elemente eine spannungsvolle Beziehung ein. Kein Zweifel, der Bauherr wollte nicht nur seine Nachbarn beeindrucken, sondern auch diejenigen Reisenden, die das Engadin auf der Talstrasse passierten. 1999 bauten wir das Haus für zwei Familien zu deren zweitem Wohnsitz um. Die Fassaden blieben unverändert; im Innern bauten wir einige wenige Räume und Elemente in zeitgenössischer Formensprache ein, die durch Abstände von den alten Mauern und Böden getrennt sind. Diese neuen Raumschalen enthalten Bäder, Lift und Treppen - Funktionen, die im Wohnteil gravierende Eingriffe erfordert hätten. Die Leitungen liegen in den Zwischenräumen. Indem wir das räumlich und technisch Neue in unabhängige Teile auslagerten, schonten wir die alte Substanz. Zudem bilden Alt und Neu interessante Konfrontationen, etwa bei den Übergängen oder dort, wo man alte Mauern und Wände durch die neue
Schale hindurch betrachten kann. Da die Familien verwandt sind und sich gut kennen, konnten wir wichtige innere Verbindungen beibehalten. So kann man das Haus, etwa bei speziellen Anlässen, noch als Ganzes erleben und durch die faszinierenden Raumfolgen schreiten. Die eine Familie betritt das Haus über den Sulèr, im Winter über die Cuort. Sie bewohnt alle Räume im Erdgeschoss des ehemaligen Wohnteils sowie die Schlafkammer im ersten Obergeschoss, in die man von der Stube über den Burel hochsteigt. Die Küche befindet sich am ursprünglichen Ort im Erdgeschoss. Der gewölbte Saal im Erdgeschoss, der um 1800 in den Sulèr eingebaut worden war, dient als Schlafraum. In jenen Teil des Sulèr, der an den Heustall grenzt, schoben wir einen eigenständigen Block mit neuen Bädern ein. Davon ist eines direkt mit dem saalartigen Schlafzimmer verbunden, das andere dient den übrigen Schlafzimmern. Die zweite Familie tritt durch den Heustall ins Haus. Auch hier bauten wir ein unabhängiges Raumelement ein. Dieser Block nimmt die neuen vertikalen Verbindungen auf, Treppe und Lift. Im ersten Obergeschoss enthält er zwei Bäder, von denen eines wiederum direkt mit einem Schlafzimmer im alten Wohnteil verbunden ist. Zuoberst im neuen Bauteil blieb Platz für eine Sauna und einen Fitnessraum. In der alten Chamineda platzierten wir die Küche, die mit einer Eisentüre geschlossen wird. Das Prunkstück dieses Hausteils ist die mit Intarsien veredelte Stüva sura, an die ein Alkoven anschliesst. Auch die beiden einstigen Knechtenkammern im Dachgeschoss gehören zu dieser Wohnung. Für die Autos fanden wir Platz im ehemaligen Viehstall; die Garage ist direkt mit beiden Wohnungen verbunden. 

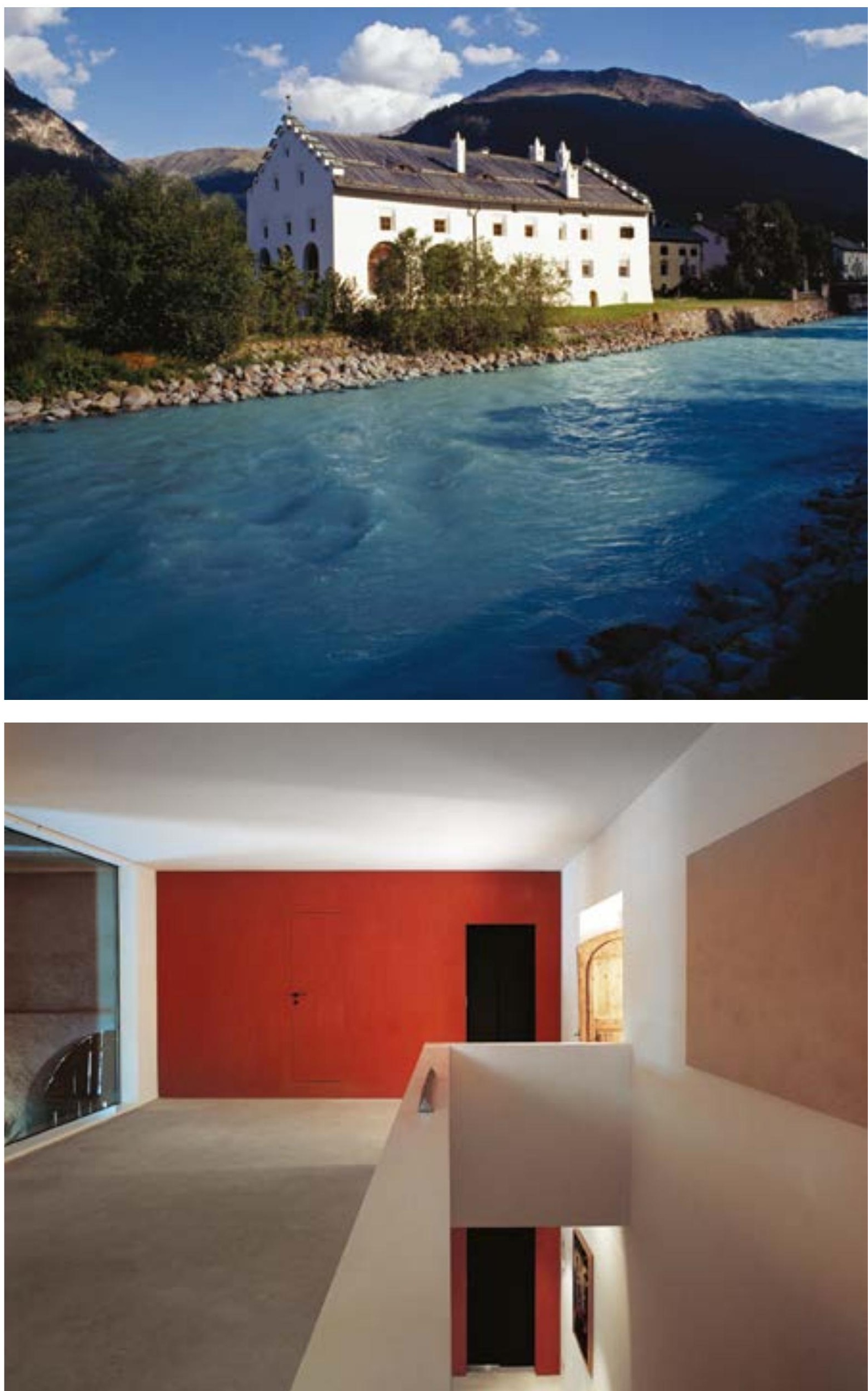

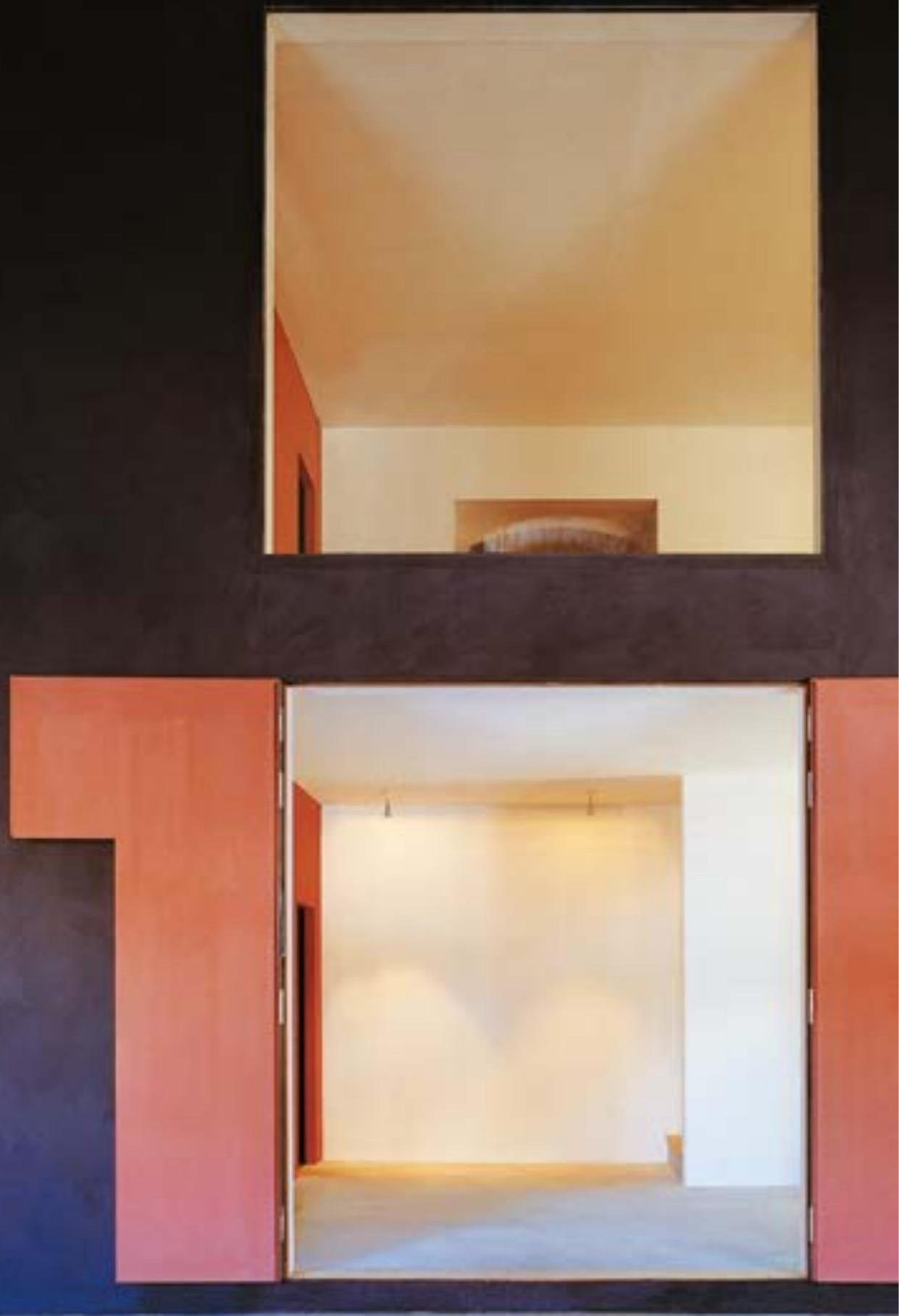

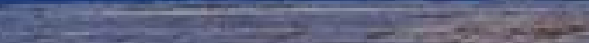

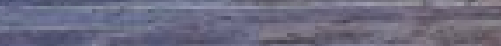



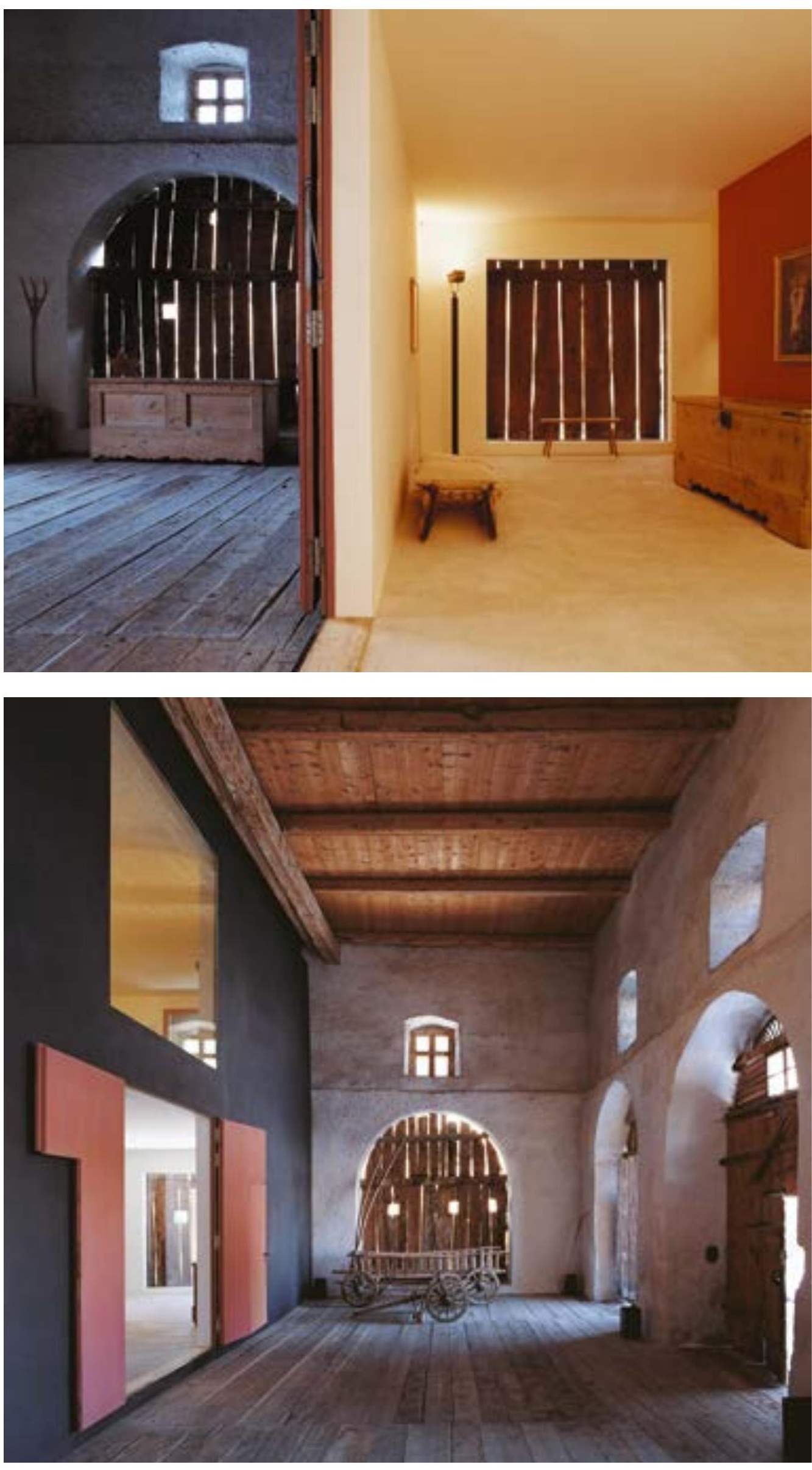


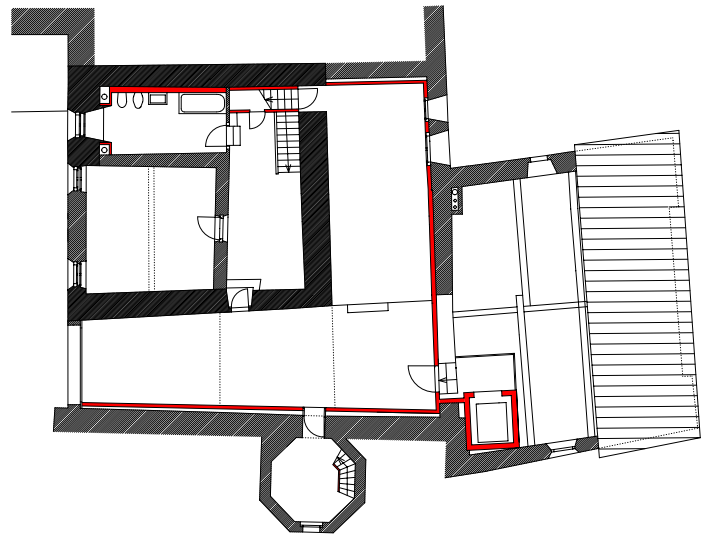

\section{Chesa Madalena, Zuoz}

Erbaut um 1304, ausgebaut um 1510, erweitert um 1593, restauriert und umgebaut 2001/2002.

Das Ortsbild des spätmittelalterlichen Zuoz war von einer grossen Anzahl unterschiedlich hoher steinerner Wohntürme geprägt, was die einstige Bedeutung von Zuoz als Hauptort des Oberengadins bezeugt. In der Mehrzahl dürften sie von den führenden Familien im Ort erbaut worden sein; dendrochronologische Untersuchungen weisen ihre Entstehung im 14. Jahrhundert nach. Wegen ihrer massiven Bauweise im Schwabenkrieg von 1499 meist nur beschädigt, wurden die Wohntürme später in die neuzeitlichen Engadinerhäuser integriert. Bei Umbauten werden nun immer wieder solche wertvollen Bauteile entdeckt. Auch die Chesa Madalena gehört zu jenen Bauten, die sich aus einem mittelalterlichen Turmbau entwickelten und zu einem Bauernhaus nach Engadiner Schema ausgebaut wurden. Der Wohnturm in der Chesa Madalena misst im Grundriss $10 \times 10 \mathrm{Me}-$ ter und ist mit etwa 16 Metern Höhe der höchste erhaltene Turm in Graubünden. Sein ursprünglicher Abschluss wurde abgetragen und angepasst, als die Dachform des heutigen Hauses entstand. Die Ecken des Turms und die Gewände seiner Öffnungen bestehen aus markanten Sandsteinquadern; woher der Sandstein kam, ist nicht bekannt. An den Innen- und Aussenwänden sind grosse Teile des ursprünglichen Pietra-rasa-Verputzes erhalten, bei dem mittels eines in den noch feuchten Mörtel gezogenen Fugenstrichs eine Quaderimitation auf die Wandflächen gezeichnet wurde. Zuoberst im Turm befand sich ein eingemauerter, verkohlter Balkenstumpf der ursprünglichen Balkenlage, dessen Fälldatum dendrochronologisch auf das Jahr 1304 festgelegt werden konnte. 1999

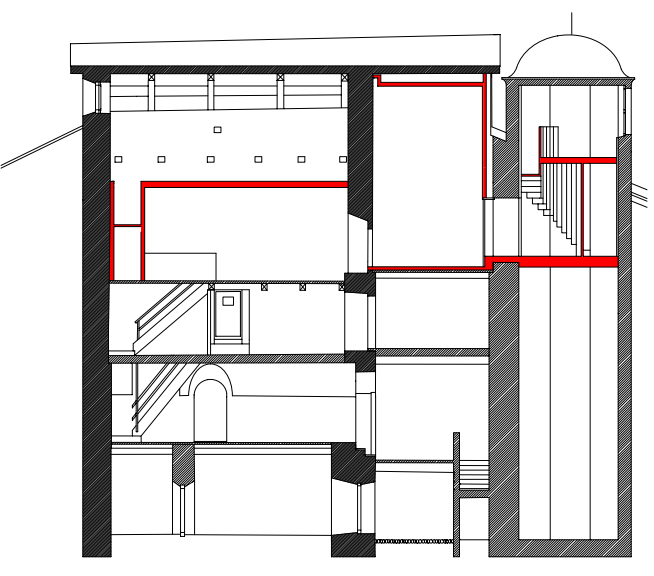

legte die Denkmalpflege Graubünden in der Ostwand eine zugemauerte Rundbogentüre frei, den Eingang zum Erdgeschoss des Turms. Direkt gegenüber im Nachbarhaus fand man ebenfalls eine Öffnung; dies deutet darauf hin, dass die beiden heute aneinandergefügten Bauten ursprünglich durch eine Gasse getrennt waren. Vermutlich ist auch im Nachbarhaus eine Turmanlage verborgen. Bei der Chesa Madalena konnte man mittels Dendrochronologie zwei weitere Bauphasen bestimmen: Um 1510 wurde die innere Struktur des Turms wiederaufgebaut, um 1593 die Gasse überbaut sowie ein Vieh- und darüber ein Heustall angegliedert - so entstand das Bauernhaus, das über vierhundert Jahre lang bewirtschaftet werden sollte. 1999 erwarb der heutige Eigentümer die Chesa Madalena. Der mittelalterliche Wohnturm war kaum sichtbar und schwierig zu erfassen, denn in den letzten hundert Jahren waren auf verschiedenen Ebenen um und im Turm diverse Kammern eingebaut worden. Gemeinde und Denkmalpflege erlaubten uns, in einem ersten Schritt alle historisch unbedeutenden Bauteile zu entfernen. Behutsam legten wir den Turm frei und planten erst dann, sorgfältig in die historische Substanz eingepasst, die wenigen neuen Teile, die der Umbau in ein Wohnhaus mit Kunstgalerie erforderte. Ursprüngliche Leer- und Kalträume wie Viehund Heustall sowie den Raum unter dem Dach des Turms konnten wir leer und kalt lassen; die Kunstgalerie nutzt sie als Ausstellungsräume. Eine Bereicherung ist das Türmchen im benachbarten Gemeindehaus, dessen oberen Teil wir mit der Chesa Madalena verbinden konnten. $\mathrm{Zu}$ Beginn des 20. Jahrhunderts entstanden, diente es lange zum Aufhängen der Feuerwehrschläuche. Es bietet eine prächtige Aussicht über Dorf und Tal. 

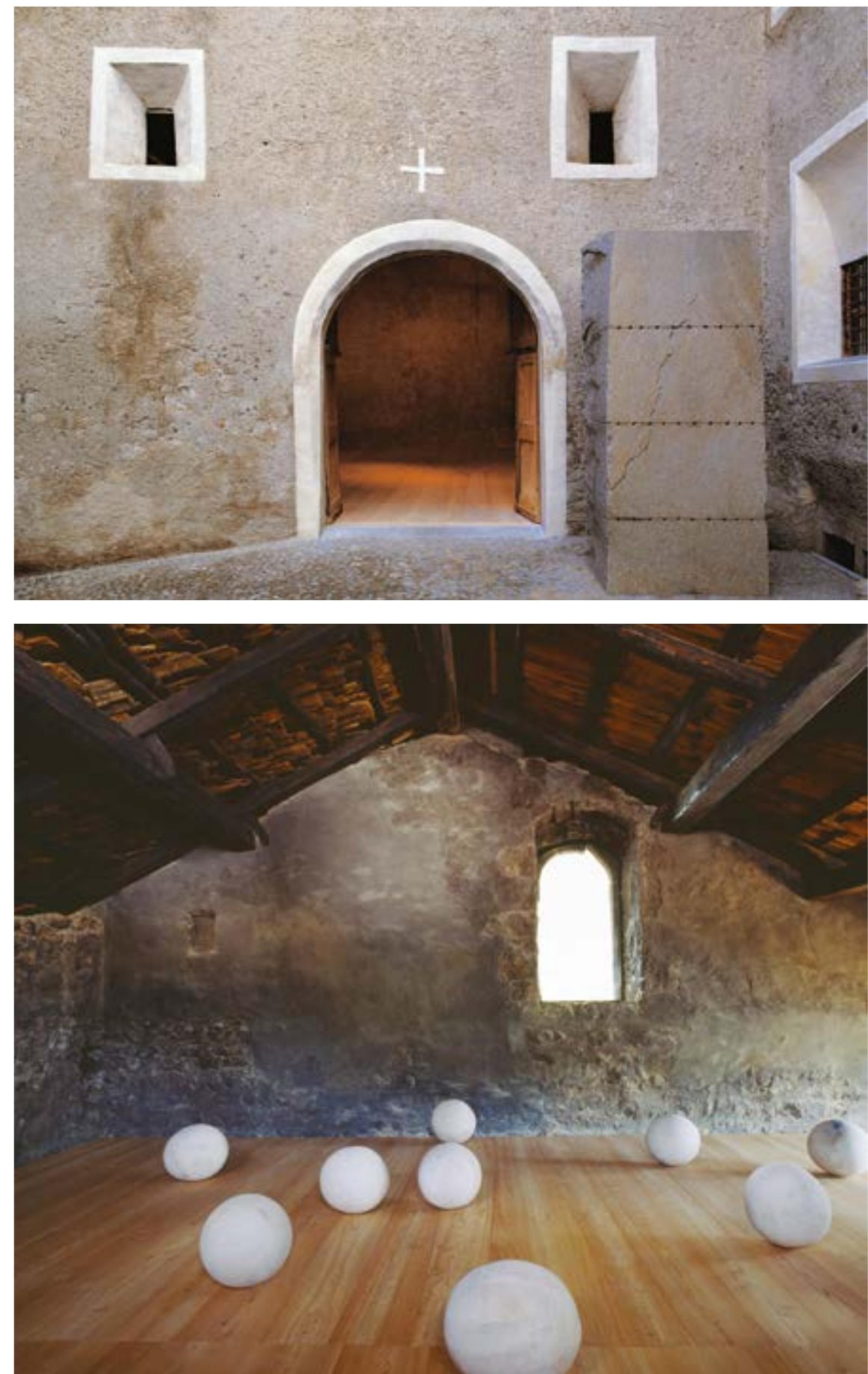

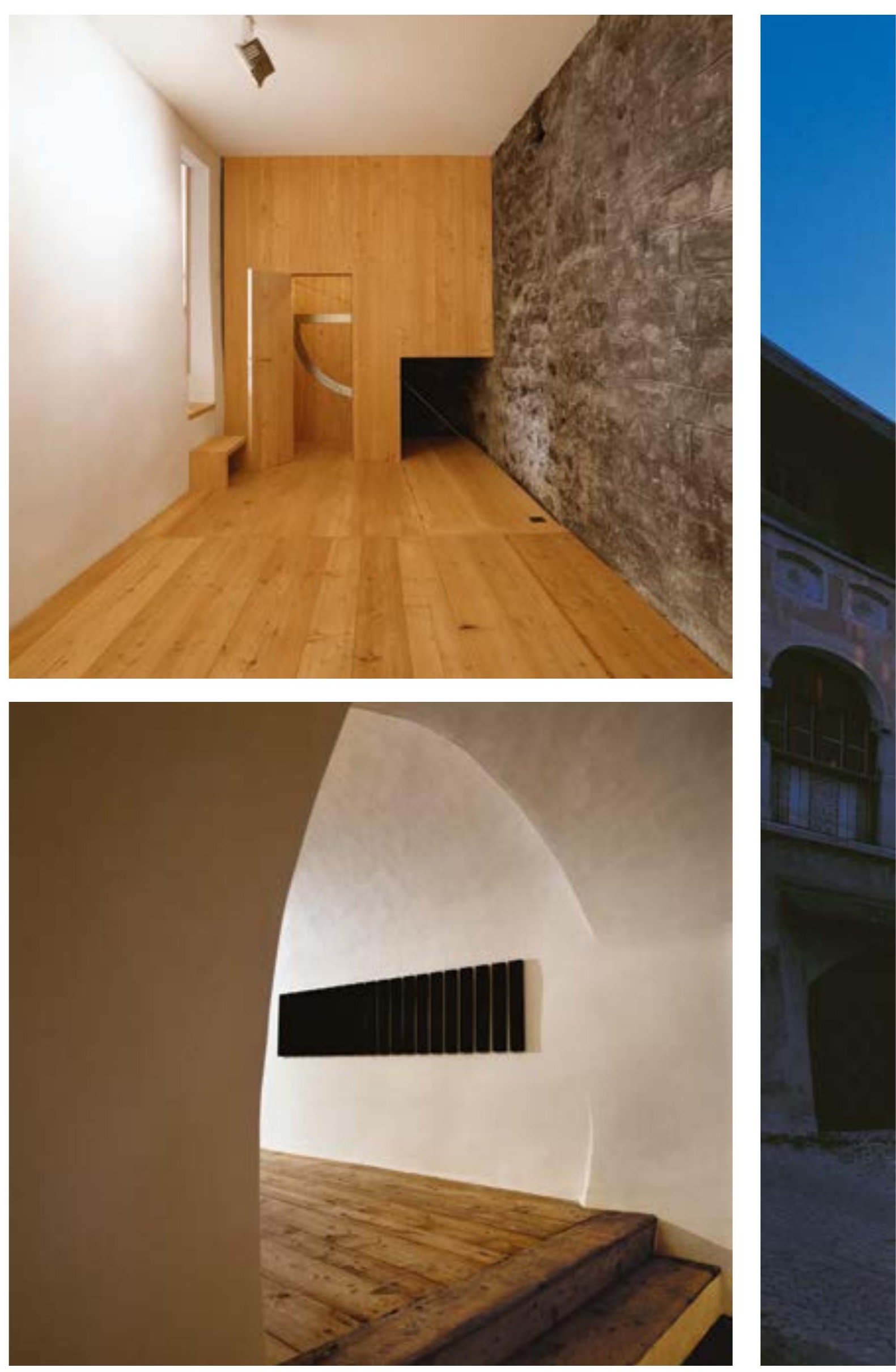


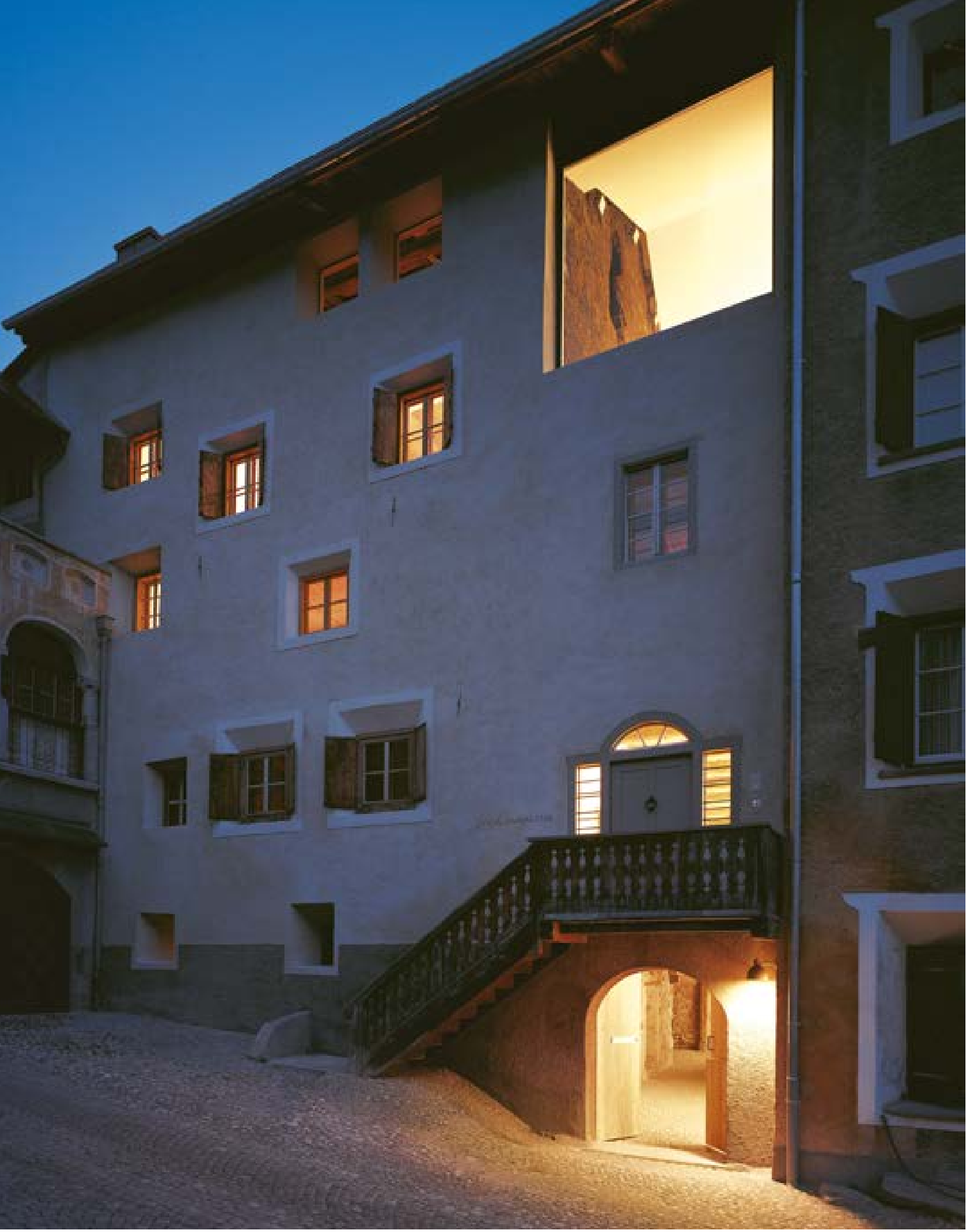




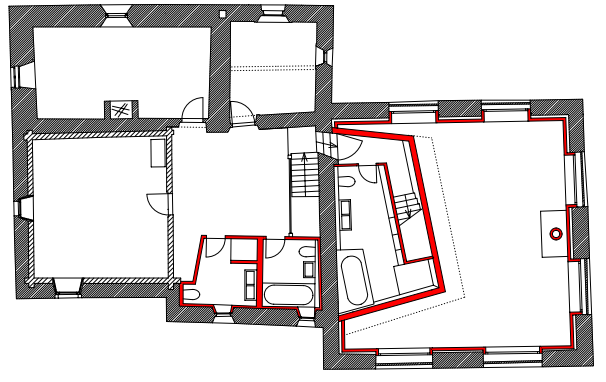

\section{Chesa Büsin, Silvaplana}

Erbaut wohl im 16. Jahrhundert, erweitert im 18. Jahrhundert, restauriert und umgebaut 2003/2004. Die Chesa Büsin steht am Rand des historischen Dorfkerns von Silvaplana, direkt an der Strasse zum Julierpass. Dendrochronologische Analysen weisen auf den Ursprung des Gebäudes in den 50er-Jahren des 16. Jahrhunderts hin. Damals entstand zumindest die im Haus integrierte Strickkonstruktion mit Stube und darüberliegender Schlafkammer, samt dem gemauerten Unterbau, der als Keller diente. Nur wenig später mag die nachträglich wohl erneuerte Stallscheune errichtet worden sein. Vermutlich erst in einer dritten Etappe wurde der Raum zwischen Ökonomie- und Wohntrakt geschlossen, wodurch sich im Untergeschoss eine Cuort und im darüberliegenden Stock ein Sulèr bildete. In nur wenigen Jahrzehnten scheint so aus einem Hof mit einzelnen Häusern ein kompakter Sammelbau mit Wohn- und Wirtschaftstrakt entstanden zu sein. Die Chesa Büsin ist zwischen zwei Nachbarhäusern eingeklemmt. Die einzige Öffnung, die Aussicht und Besonnung verspricht, ist deshalb ein Fenster im Giebelfeld des Heustalls nach Südwesten. Wir wollten das Haus nicht «auf den Kopf stellen», um die heutigen Bedürfnisse nach Licht und Sonne zu befriedigen. Deshalb wurde das Fenster zuoberst in der Scheunenwand zum Ausgangspunkt unseres Entwurfs. Wir bauten einen Raum zu diesem Fenster, ein grosses Schlafzimmer mit Bad, und hängten dieses Raumpaket wie einen Rucksack in den Heustall hinein, befestigt an der Mauer, welche die Scheune vom Wohnteil abtrennt. Vom Obergeschoss des Wohntrakts führt eine neue Türe in diesen «Rucksack». Das alte Fenster, auf diese Weise in den Entwurf integriert, bietet nun eine spektakuläre Aussicht

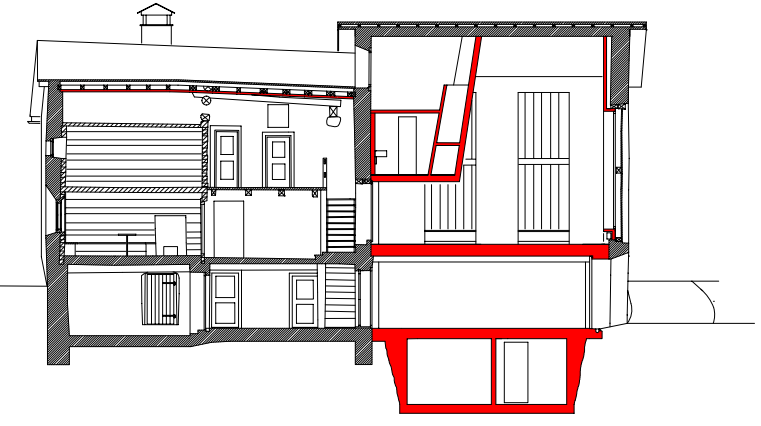

über die alten, mit Steinplatten belegten Dächer Silvaplanas zum Piz Corvatsch. Der Heustall mit dem eingehängten «Rucksack» dient seit dem Umbau als Wohnraum. Wir verglasten die hohen Öffnungen; die davor angebrachten Holzlamellen sind im oberen Teil mit einem Drehmechanismus versehen. Stehen sie schräg, geben sie den Blick frei auf Berge und Himmel. Die Privatsphäre bleibt aber gewahrt, denn im unteren Bereich bleiben die Lamellen fest und lassen nur schmale Lichtschlitze offen. Im historischen Wohnteil räumten wir die neueren Einbauten und Materialien aus. Der eindrückliche Strickbau mit Stube und Kammer bildet wieder den Kern des Hauses. Die beiden Räume sind in ihrem ursprünglichen spätgotischen Zustand erhalten. So steht in der Stube noch der alte gemauerte Ofenblock mit dem schmalen Burel, dem Aufgang in die Schlafkammer. Die Küche bauten wir in den nördlichen Anbau ein. Im Obergeschoss entwarfen wir zwei Badezimmer als weissen Block, der als neuer Einbau ablesbar ist. Ein weiteres Schlafzimmer liegt im Untergeschoss; das dazugehörige Bad richteten wir in einem bestehenden, überwölbten Raum ein. Schliesslich bauten wir den Viehstall zu einer unterkellerten Garage um - die Zufahrt ist zwischen die Häuser eingepasst - und restaurierten die Fassaden. Dabei konnten wir vier historische Trichterfenster mit beträchtlichem Aufwand wieder öffnen. Alt und Neu sind in der Chesa Büsin zu einem spannungsvollen Ganzen geformt. Entscheidend dafür ist die konsequente Art der Materialisierung: Die historischen Bauteile wurden sorgfältig und fachgerecht restauriert, die neuen Elemente präzis entworfen und in hoher handwerklicher Qualität erstellt. All diese Massnahmen trugen dazu bei, das einst unscheinbare und verlassene Haus zu neuem Leben zu erwecken. 


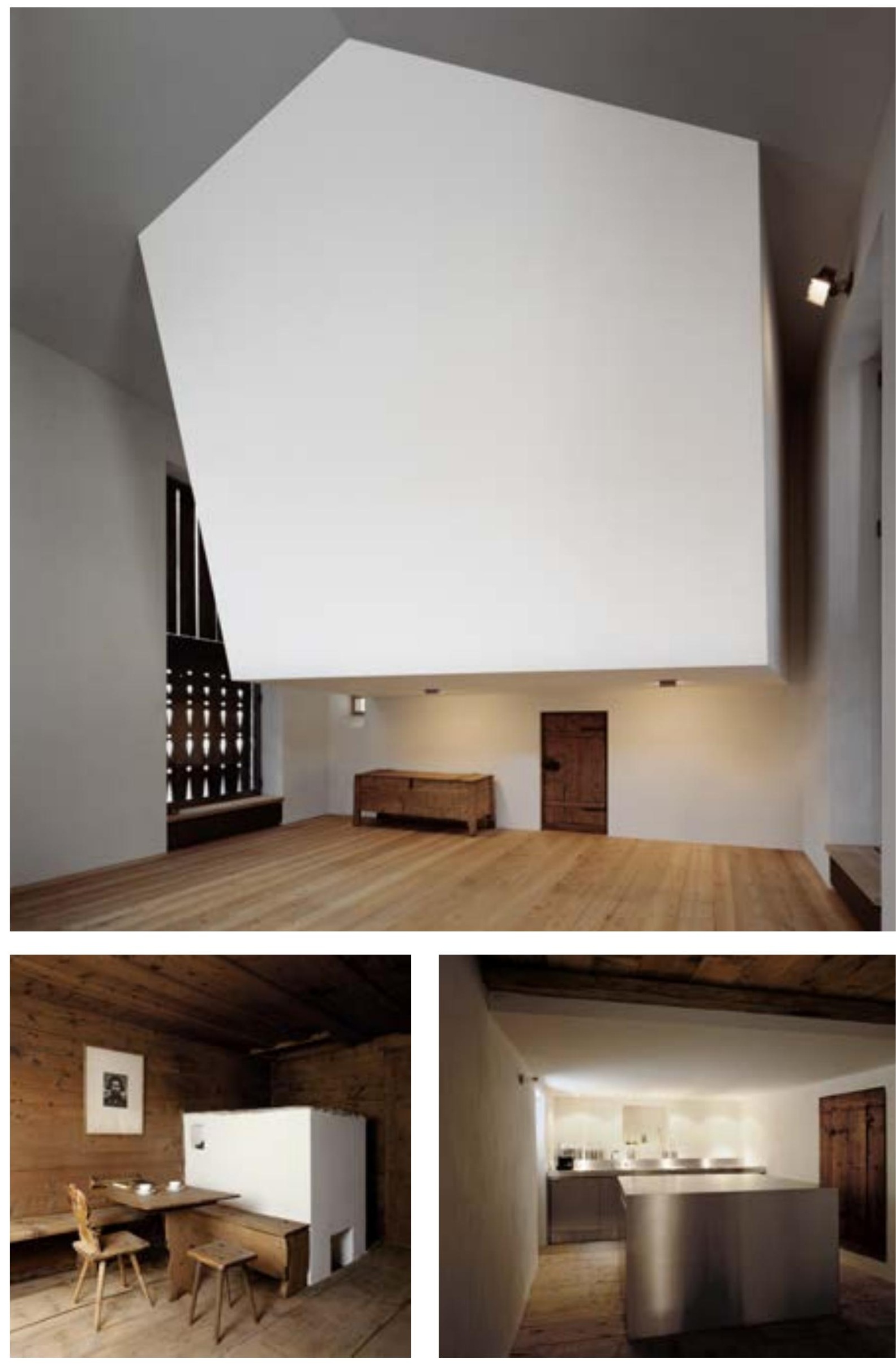



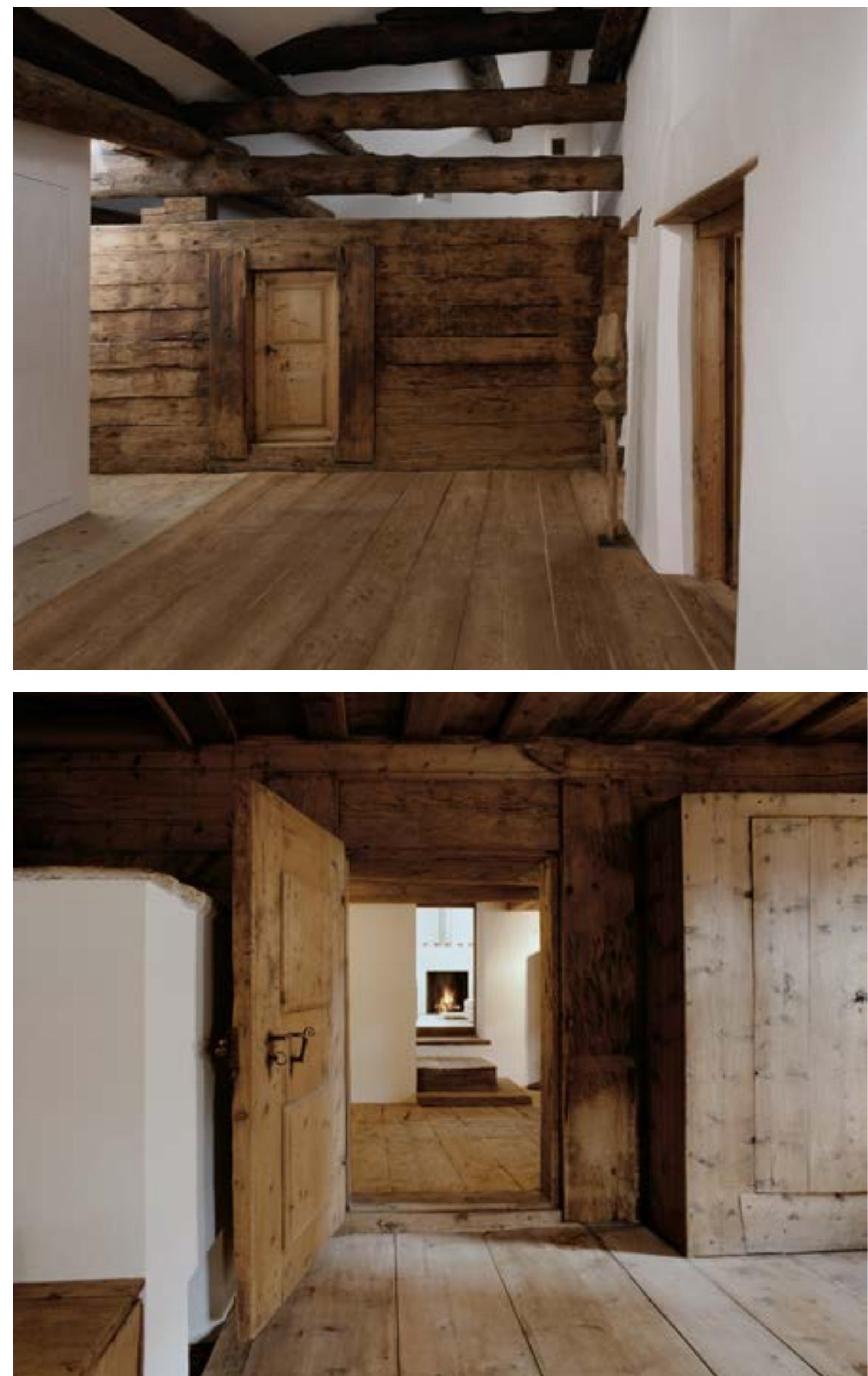

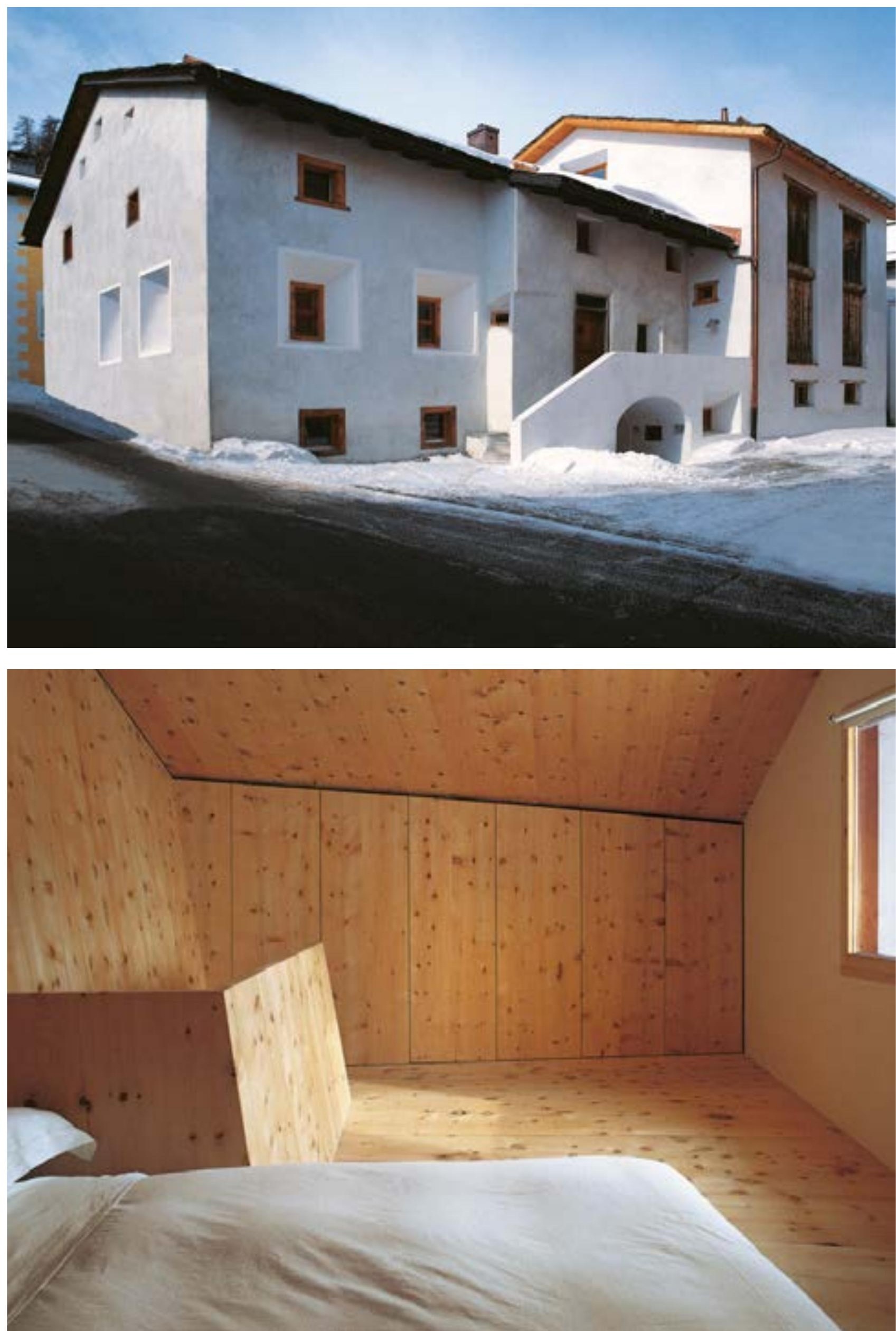

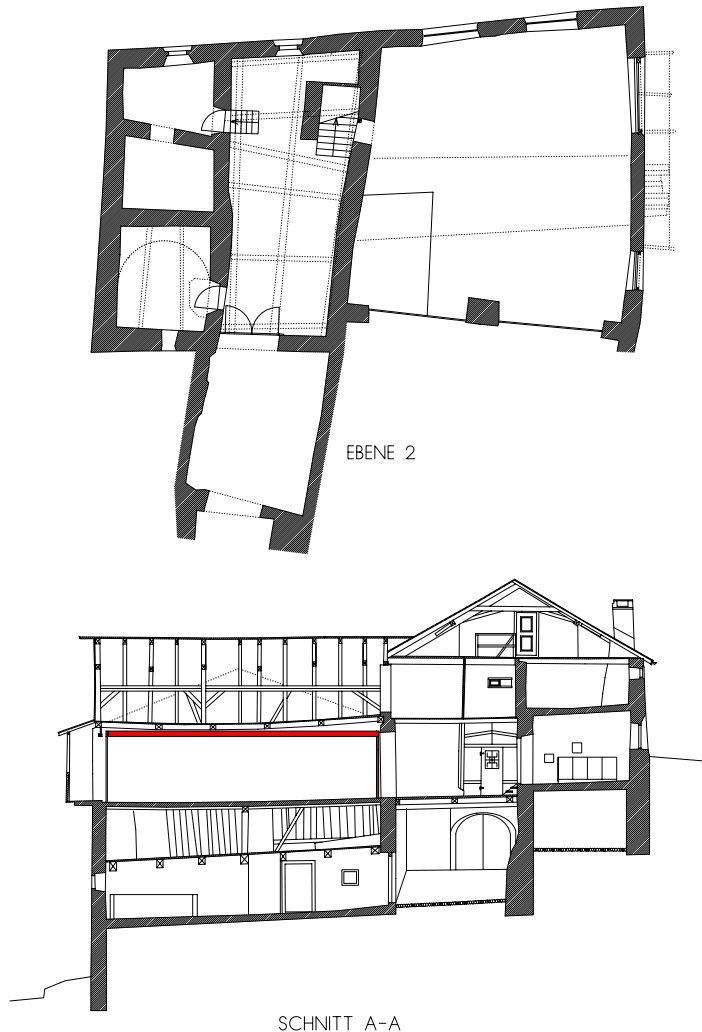

Chesa Not, Tschlin

Erbauungszeit unbekannt, renoviert nach 1856, restauriert und umgebaut 2004.

Die Chesa Not liegt neben dem frei stehenden Kirchturm und dem Friedhof des Unterengadiner Dorfes Tschlin. Zwischen dem 16. und 18. Jahrhundert entstanden, repräsentiert es den neuzeitlichen Engadiner Bautypus in nahezu klassischer Form. Allein die Position des Ökonomietrakts entspricht nicht dem Idealschema: Wegen des nördlich an die Chesa Not stossenden Gebäudes liess er sich nicht rückwärtig angliedern, sondern musste seitlich an den Wohntrakt angebaut werden. Dieser steht parallel zum stark abschüssigen Hang, die Stallscheune hingegen quer dazu, was zur Folge hat, dass man die Grösse des Gebäudes kaum wahrnimmt. Auffällig sind die markanten, abstrakt wirkenden Einfassungen der Fenster in Kobaltblau. Der Künstler Not Vital - er ist in Sent geboren - hat eine Passion für alte Gebäude und kaufte das Haus. Er erkannte das Potenzial des Hauses, das sich ohne massive Eingriffe zum Wohn- und Atelierhaus umnutzen liess. Dafür war nicht, wie üblich, das Dämmen und Beheizen des ganzen Gebäudes, sondern nur die Schaffung eines warmen Kerns nötig. Die übrigen Räume bewohnt Vital, wenn es die Jahreszeit erlaubt. Ansonsten dienen sie als Räume für seine Kunstwerke oder für Werke befreundeter Künstler.
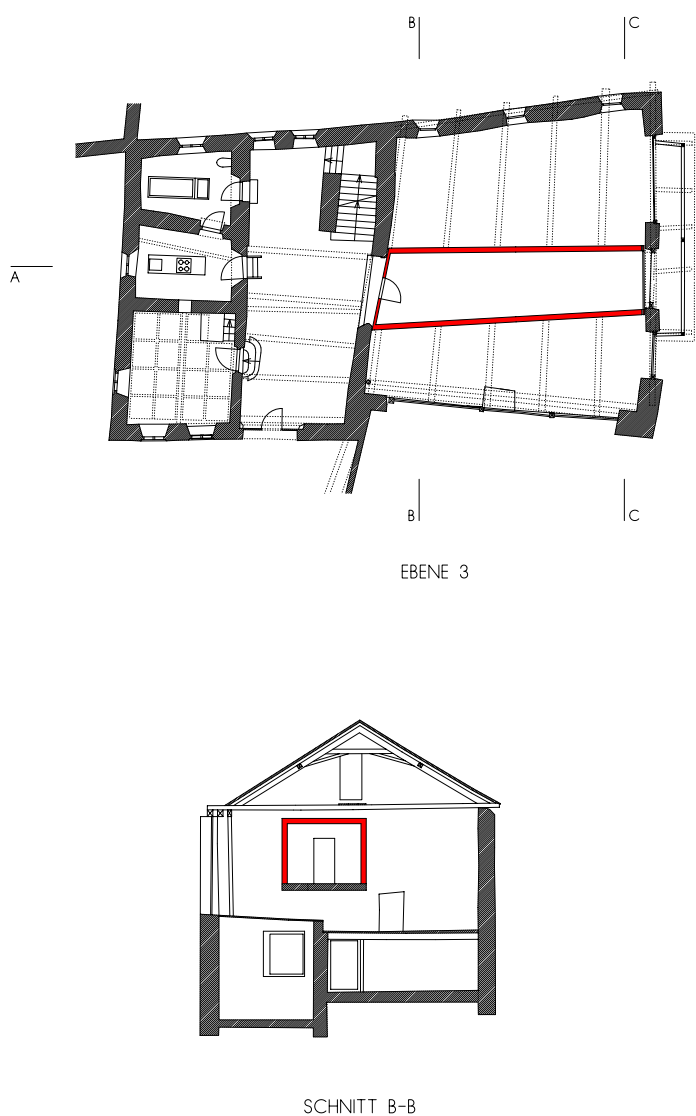

Wir bauten die bestehende Heubühne, ihrer Geometrie folgend, zu einem Raum aus, der im Heustall hängt und ihn vom Sulèr Richtung Tal durchdringt. Es handelt sich um eine Pfostenriegelkonstruktion mit gedämmten Zwischenräumen. Innen ist das Zimmer vollständig mit heimischem Arvenholz ausgekleidet; die äussere Hülle bildet eine Schicht Bitumen, pechschwarz und je nach Lichtsituation speckig schimmernd. Der Raum wurde zum Fernrohr für die spektakuläre Aussicht. Trotz dieses eingehängten Zimmers ist die eindrückliche Grösse der Scheune noch wahrnehmbar, denn um den mit Bitumen bestrichenen Block gibt es viel Luft. Am Sulèr sind die übrigen beheizbaren Räume aufgereiht. Stube und Küche werden in ihrer ursprünglichen Funktion genutzt; die ehemalige Chamineda wurde von Duri Vital, dem Bruder des Bauherrn, zum Bad ausgebaut. Den Küchenkorpus und den Einbau im Bad mit Badewanne und Lavabo liess er aus 5 Millimeter dicken Chromstahlplatten anfertigen. Die Patina der Oberflächen und sogar der Russ in der Küche wurden kompromisslos beibehalten. Im archaisch anmutenden Untergeschoss füllte Not Vital eine zentral gelegene Vertiefung mit Wasser. So entstand ein kleines Schwimmbad, das im Winter vereist. Die kobaltblauen Einfassungen der Fenster beliessen wir; sie verleihen den weiss gekalkten Fassaden einen aussergewöhnlichen Charakter. 

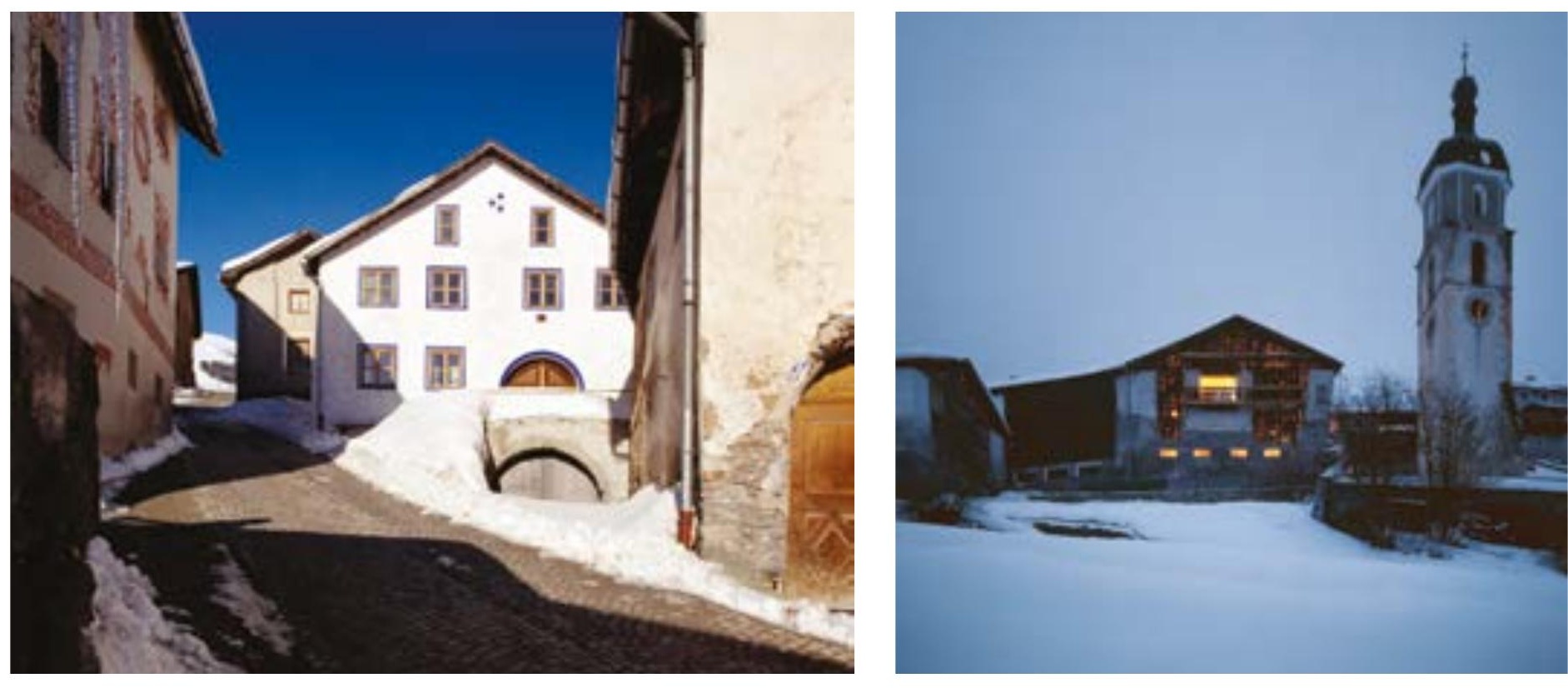


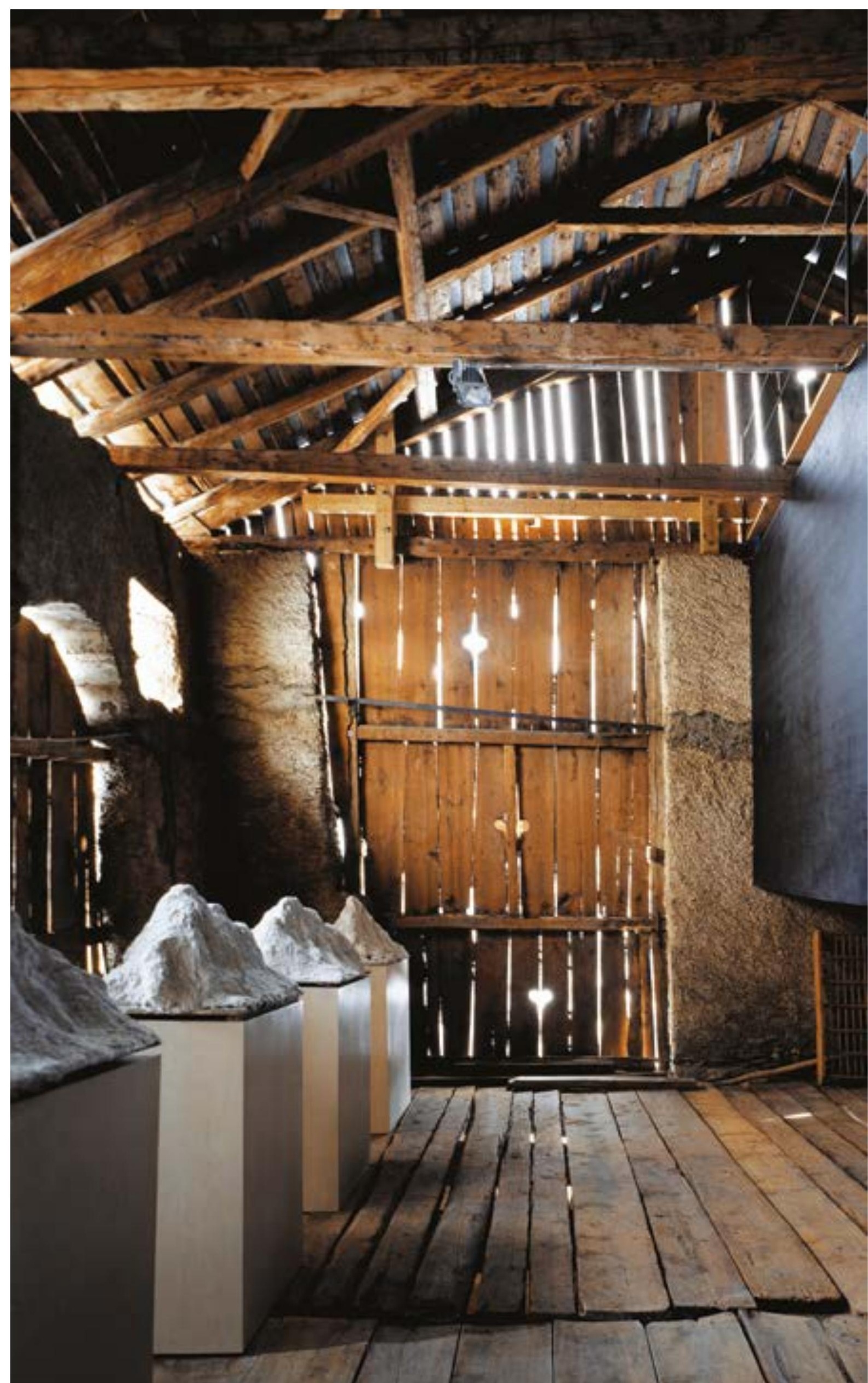



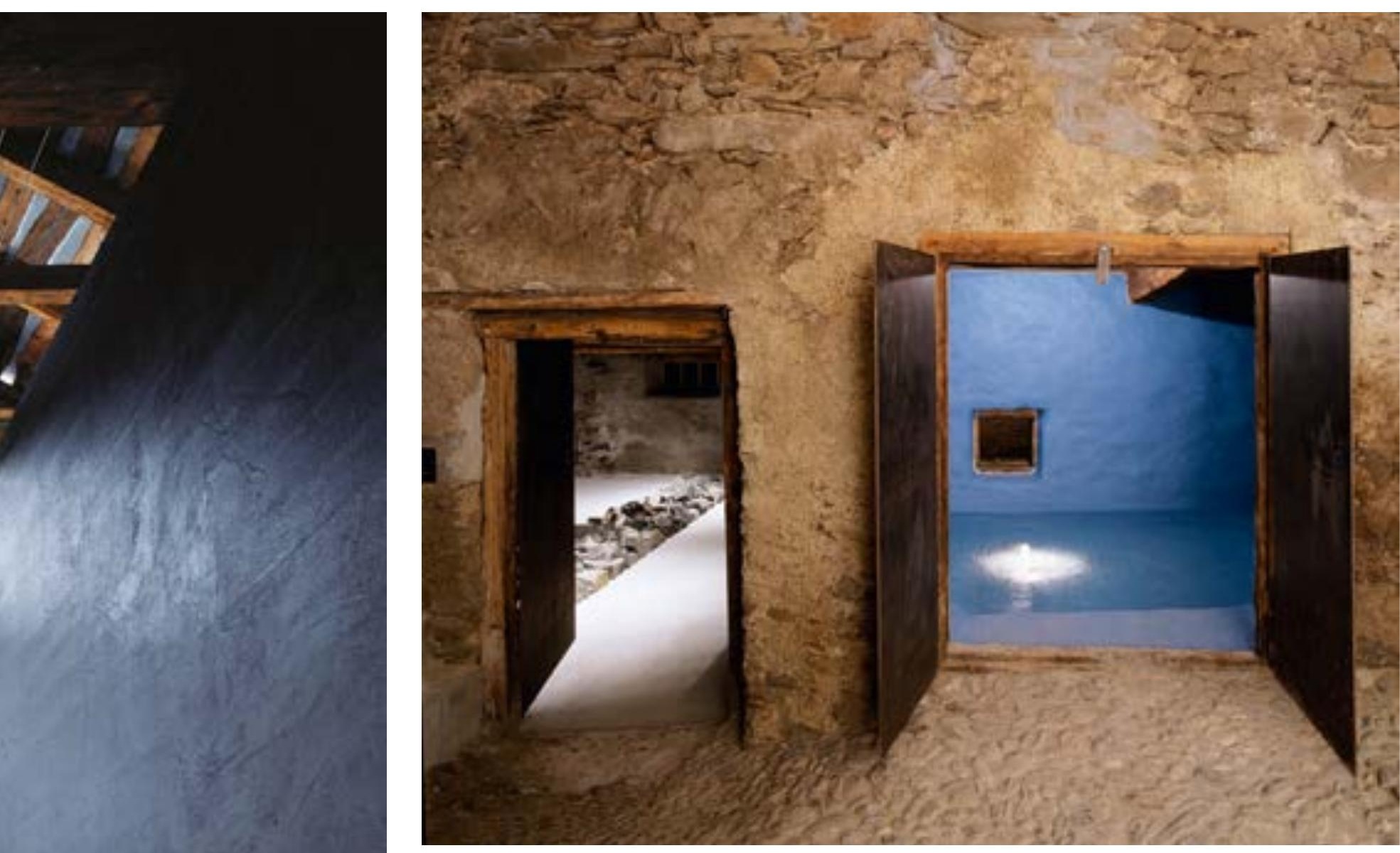